\title{
The Role of Probiotics in Atopic Dermatitis Prevention and Therapy
}

\author{
Öner Özdemir \\ Republic of Turkey, Ministry of Health, İstanbul Medeniyet University \\ Göztepe Research / Training Hospital \\ Turkey
}

\section{Introduction}

Development of the child's immune system tends to be directed toward a T-helper 2 (Th2) phenotype in infants, whereas postnatal maturation is associated with gradual inhibition of Th2 and increasing Th1 affinity [1]. Thus, immature Th2-dominant neonatal responses must undergo environment-driven maturation via microbial contact in the early postnatal period to prevent development of childhood allergic diseases. Nevertheless, nowadays the increased use of antimicrobial medication, the consumption of sterile food, and reduced family size that result in lower rates of infection during childhood also reduce early contact to microbes. Consequentially, at an early age the infant's immune system results in subsequent polarization toward a Th2 phenotype during postnatal maturation. Among several other phenomena, the present increase in allergic diseases seen in the industrialized countries has been attributed, to a relative lack of microbial stimulation of the infantile gut immune system and the exaggerated hygiene of the typical western lifestyle during early childhood. And this is known as the hygiene hypothesis [2].

The newborn is first colonized by microbes at birth. The colonization of the gut that begins promptly after birth is affected by mode of delivery, early feeding strategies and the hygienic conditions around the child (the early environment). The colonizing bacteria originate mainly from the mother's gut and vaginal tract [3]. For instance, children born by cesarean section are colonized with Bifidobacteria and Lactobacilli later than vaginally delivered children, and are shown to have more frequent respiratory allergies [4]. After delivery, breastfeeding continues to enhance the original inoculum by the introduction of specific lactic acid bacteria, Bifidobacteria and bacteria from the mother's skin, all of which enable the infant gut microbiota that is dominated by Bifidobacteria. Breast milk also contains plentiful indigestible oligosaccharides, which pass through the whole intestine and promote the growth and activity of commensal bacteria; composed mainly of Bifidobacteria [5]. These bacteria set the basis for gut microbiota development and modulation, along with environmental exposures such as antibiotic administration.

The greatest differences between breast-fed and formula-fed infants appear to be in lactic acid bacteria and Bifidobacteria colonization. Usually, Bifidobacteria appear after birth and, within a week, are reported as the dominant bacterial group, with Bifidobacterium (Bfdbm) infantis / longum / breve being the most common species in breast-fed infants [6]. In addition, Lactobacillus (Lctbs) acidophilus is the most common Lctbs in the feces of breast- 
fed infants. Formula-fed infants, on the other hand, tend to have a flora that is more complex, consisting mostly of Coliforms and Bacteroides, with significantly lower the prevalence of Bifidobacteria [7]. After weaning, the microflora of children begins to resemble that of adults, with increased Bacteroides, Veillonella, and Fusobacterium [8].

Epidemiologic data showed that atopic children have a different intestinal flora from that of healthy ones, with higher levels of Clostridia and lower levels of Bifidobacteria. Furthermore, other studies have also shown that early colonization with potentially more pathogenic bacteria such as Clostridium difficile and Staph. aureus is more likely to occur in children who go on to develop allergy. In contrast, lactic acid bacteria and Bifidobacteria are found more commonly in the composition of the intestinal flora of non-allergic children. The enhanced presence of these probiotic bacteria in the intestinal microbiota seems to correlate with protection against atopy $[9,10]$. Based on these data, "harmless" microbial agents that are probiotics have been presently tested for their efficacy in the prevention and therapy of allergy in infants [11-14].

The interest in probiotic therapeutic potential in allergic disorders stemmed from the fact that they have been shown to improve intestinal permeability and reduce inflammatory cytokines. Such effects would be desirable in treating allergic disorders including atopic dermatitis (AD). Therefore, several studies have been designed to examine the efficacy of probiotics in many allergic conditions, such as eczema and food allergies $[13,14]$. Including the first publication in 1997, over 30 randomized, double-blind, placebo-controlled clinical trials have been conducted to study the effects of various probiotics on treatment and prevention of allergic diseases. In total, almost 3000 individuals (including those in placebo groups) have participated in these studies so far. In the first-time study done by Majamaa and Isolauri in 1997, the administration of LGG to highly selected patients (age <2 years, challenge-proven cow's milk allergy, and mild-to- moderate eczema) significantly improved the total SCORAD score [15]. Later the Finnish study of Kalliomaki was the first report to describe that the frequency of AD in neonates treated with Lctbs rhamnosus GG (LGG) was half that of the placebo [16]. However, these results recently have been questioned by other trials, which reported no difference in the development and therapy of AD in neonates supplemented with LGG or other probiotics. Therefore, an allergen-preventive or therapeutic effect of probiotics in AD could not be consistently established. The aims of this chapter are to comprehensively define probiotic properties and to characterize current knowledge of probiotics, including the key mechanisms of probiotic effects as well as their preventative/ therapeutic role in AD at last.

\subsection{What are probiotics?}

The year 2011 marks the 104nd year since Eli Metchnikoff suggested that the consumption of lactic acid bacteria may benefit the human host's immune system [11]. However, not until the mid-1960 did the term probiotic become the trend. Probiotics means "for life" and is defined by the World Health Organization and the Food and Agriculture Organization of the United Nations as "live microorganisms which, when administered in adequate amounts as part of food, confer a beneficial health effect by producing gut microflora on the host." These probiotics are mainly represented by lactic acid bacteria [12]. Simply; probiotics are ingested live microbes that can modify intestinal microbial populations in a way that benefits the host.

\section{Characteristics of probiotics}

There are several generally accepted characteristics that define probiotic bacteria. Probiotics:

- $\quad$ are microbial organisms; 
- $\quad$ remain viable and stable after culture, manipulation, and storage before utilization;

- $\quad$ survive gastric, biliary, and pancreatic digestion;

- $\quad$ are able to induce a host response once they enter the intestinal microbial ecosystem; and

- $\quad y i e l d$ a functional or clinical benefit to the host when consumed [10-16].

\subsection{Atopic dermatitis (eczema)}

Atopic dermatitis (AD) is the most common chronic skin condition in infants and children, with a prevalence of $10-20 \%$ in population. Geographic location affects the prevalence of this disease, with the highest prevalence in the United States and Europe [17]. Important factors in the susceptibility to develop AD include a genetic basis and environmental factors. Eczema refers to a chronic or relapsing itchy skin inflammation with typical lesions and locations. AD has been linked to food hypersensitivity, especially milk and egg proteins. However, $40-60 \%$ of children with AD may not develop IgE sensitization [18]. The term eczema has been recently proposed, but for practical purposes, both AD and eczema will be used in this chapter.

There have been several proposed methods for classifying the severity of $\mathrm{AD}$ in various research studies mentioned in this chapter, but only the Scoring of AD Severity Index (SCORAD), established by the European Task Force on AD, has been validated for reproducibility and accuracy in assessing therapeutic response $[17,18]$. The SCORAD combines objective measures, such as extent and severity of skin lesions, and subjective criteria, such as pruritus and sleep loss. Children with AD can be further classified as having mild: ( $\leq 25)$, moderate: $(25-50)$, or severe: $(\geq 50)$ disease based on their SCORAD score.

\section{Experimental and clinical essentials of preventative and therapeutic probiotic use in $A D$}

As briefly mentioned above, there is a good experimental and clinical theoretical basis for using probiotics in the prevention and therapy of AD. Germ-free animal models demonstrate that bacterial gut colonization is essential for maturation of immune function and induction of oral tolerance. It has been proposed that a similar but more subtle process may be occurring in human beings with progressively cleaner environments. Probiotic intestinal flora is arguably the most abundant source of early immune stimulation and contributes significantly to microbial burden in early life. A number of studies have suggested differences in the early colonization patterns of infants who go on to develop allergic disease. These studies strongly suggest that the pattern of colonization in the first weeks of life may influence the patterns of immune development $[19,20]$. These notions have been supported by observations that gut flora can influence local and systemic immune responses. There has been speculation that intestinal flora may influence the maturing precursor cells that circulate through the gut before they home to other tissues. This may explain how probiotic species can influence systemic immune responses and IgA production in distal sites, such as the respiratory tract. Together with reported clinical effects in early allergic disease, this has logically led to a growing interest in the role of probiotics in allergy prevention $[13,14]$.

The gastrointestinal tract of the newborn baby is sterile. Soon after birth, however, it is colonized by many different microorganisms. Colonization is complete after around one week, but the numbers and species of intestinal bacteria fluctuate markedly during the first 
several months of life. The composition of the gut microbiota differs between healthy and allergic infants and even in countries with a high and low prevalence of allergies [21]. Mode of delivery, either vaginal or through caesarean section, also has a major impact on early colonization patterns of the infant gut [4]. In the case of allergy, the rationale for modulating the intestinal microbiota is supported by observations that allergic children have a different microbiota composition than healthy infants. The main changes associated with allergic trait are less frequent colonization with Lactobacilli and lower counts of Bifidobacteria [9,22]. In addition to these quantitative differences in the Bfdbm microbiota, qualitative differences have also been observed. Infants with AD have been found to have a more adult type Bfdbm microbiota with high prevalence of Bfdbm adolescentis. Healthy infants, on the other hand, were found to be colonized mainly by Bfdbm bifidum, typical for breast-fed infants $[7,8]$. The Bifidobacteria from infants with $\mathrm{AD}$ were found to induce a higher secretion of proinflammatory cytokines in vitro, whereas the Bifidobacteria from healthy infants induced the secretion of more antiinflammatory cytokines. Also, Bifidobacteria of dairy origin stimulated more antiinflammatory and less inflammatory cytokines than Bifidobacteria from allergic infants. In addition to differing in their induction of cytokines, Bifidobacteria from allergic and healthy infants also exhibited different in vitro adhesion to Caco-2 tissue culture cells and intestinal mucus. This difference in adhesion to the intestinal mucosa may result in a different or reduced stimulation of the immune system through the gut-associated lymphoid tissue [23]. Lower counts of Bifidobacteria have been reported in atopic vs nonatopic children preceding allergen sensitization. Bifidobacteria are hypothesized to more effectively promote tolerance to nonbacterial antigens, primarily by inhibiting the development of a Th2-type (proallergic) response. In a recent study, a positive change in stool colonization in atopic infants supplemented with Bfdbm lactis has been shown with a decrease of Bacteroides and E coli in the stool. Most interestingly, serum IgE correlated with E coli counts, and in highly sensitized infants, IgE correlated with Bacteroides counts [24]. Thus, certain probiotics seem to influence the gut's allergen-stimulated inflammatory response and provide a barrier effect against antigens that might otherwise ultimately lead to systemic allergic symptoms (such as eczema).

A recent prospective study from 3 European birth cohorts found, however, no differences in gut microbiota by culture-dependent analysis of fecal samples among infants developing or not developing atopic eczema and food allergy. On the contrary, a subgroup analysis of the cohort by cultivation independent techniques indicated a significantly lower diversity in the gut microbiota of 1-week-old neonates who later manifested atopic eczema than in neonates remaining healthy during the first 18 months of life, highlighting once more that classical microbiological plating techniques are inappropriate for extensive characterization of the gut microbiota [25]. Similarly, less diverse microbial communities were found among 5-year-old allergic children than among nonallergic children by using another culture-independent technique. The same study demonstrated that Bfdbm catenulatum / pseudocatenulatum prevail in nonallergic children [26]. On the contrary, this particular Bifidobacterial species was associated with atopic eczema in a nested case-control study conducted in a different age group, country, and disease population, highlighting the complexity of the situation. As the immune modulation properties of bacteria seem to be distinctly strain specific, it cannot be ruled out that the nature of the immune response induced by a specific strain plays a more important role than its classification. 
Probiotic intestinal flora contributes to microbial antigen exposure in early life and is one of the most abundant sources of early immune stimulation. Because allergic immune responses manifest early in life, there has been obvious interest in the potential benefits of modifying the gastrointestinal flora by using probiotic supplementation. However, the value of probiotics for primary prevention is controversial $[13,14]$. So far, there have been only several studies to address the role of probiotics in primary prevention, with a reported suspicious reduction in the incidence of eczema. The role of probiotics in allergy prevention has remained controversial, and there has been an urgent call for similar studies to address this further. This chapter will try to highlight the issues with probiotics in the therapy / prevention of $\mathrm{AD}$ and future of this therapy. Here, firstly newly described mechanisms of probiotic effects will be defined. Later, under the light of recent literature probiotic use in AD therapy and prevention is being discussed in detail.

\subsection{Experimental (animal) and clinical (human) studies showing mechanisms of probiotics' effects in atopic diseases including eczema}

Although the beneficial effects of probiotics on wide variety of atopic diseases have been suggested, little is known about how probiotics modulate the immune system and atopic disease development. Currently, only limited publications are available defining the effects of probiotics in murine or human models of AD. Therefore, it is important to explore the effect of probiotics in various experimental and clinical atopic disease models.

\subsubsection{Maturing gut barrier: Probiotic regulation in intestinal epithelium and upregulation of host immune responses}

Recent data indicate that commensal intestinal microbiota represents a major modulator of intestinal homeostasis. Dysregulation of the symbiotic interaction between intestinal microbiota and the mucosa may result in a pathological condition with potential clinical repercussions. For instance, it is shown that mice reared in germ-free conditions have an underdeveloped immune system and have no oral tolerance. In contrast, pathogen-free mice are capable of reconstituting the bacterial flora with Bifidobacteria and tolerance development [27].

In addition to providing maturational signals for the gut-associated lymphoid tissue, probiotics balance the generation of pro- and anti-inflammatory cytokines in the gut. After probiotic consumption, decrease in fecal a-1 antitrypsin, serum TNF- $\alpha$, and changes in TGF$\beta$ and other cytokines point to down-regulation of inflammatory mediators [28]. For instance, after a challenge study in infants allergic to cow's milk, fecal IgA levels were detected to be higher and TNF-a levels were lower in the Lctbs rhamnosus GG (LGG) applied group compared to the placebo [29]. Similarly, another study by Kirjavainen et al suggested that Bfdbm lactis Bb12 might modify gut microflora to alleviate early onset atopic eczema. And this modification was found to be compatible with reductions of serum TNF-a and fecal a-1-antitrypsin levels as well as an increase in fecal IgA level [23].

Moreover, probiotic bacteria may counteract the inflammatory process by stabilizing the gut microbial environment and the permeability barrier of the intestine, and by enhancing the degradation of enteral antigens and altering their immunogenicity [30]. This gut-stabilizing effect of probiotics could be explained by the improvement by probiotics of the immunological barrier of the intestine through intestinal IgA responses, specifically [31,32]. Consistent with these explanations, in children with food allergies, probiotics are shown to reverse increased intestinal permeability and to enhance frequently defective IgA responses [33]. 


\subsubsection{Immunomodulation: Th1/Th2 balance, IgE production and cytokines}

In addition to maturing gut barrier, certain strains of Lactobacilli and Bifidobacteria modulate the production of cytokines by monocytes and lymphocytes, and may divert the immune system in a regulatory or tolerant mode [27,34]. Nonetheless, there are still some studies showing no significant effects of probiotics on either Th1 or Th2 cell responses to allergens. Although the cytokine stimulation profiles of different probiotic strains vary, the strains isolated from healthy infants mainly stimulate non-inflammatory cytokines [35]. Therefore, it seems that changes in cytokine profile induced by probiotics may be probiotic strain- or site-specific and dependent on the experimental system used. For instance, Lctbs reuteri induced proinflammatory and Th1 cytokines; and Bfdbm bifidum/infantis and Lctbs lactis reduced Th2 cytokines [36].

Several studies have shown the immunomodulatory effects of probiotic bacteria. In one study, Bfdbm bifidum / infantis and Lctbs lactis reduced Th2 cytokines and acted as potent inducers of IL-10 production in different peripheral blood mononuclear cell cultures [37]. In another study, eight common Lctbs strains were studied with respect to induction of cytokines by the murine gut mucosa in response to a parenterally administered antigen. Lctbs reuteri induced proinflammatory and Th1 cytokines; however, Lctbs casei tended to induce IL-10 / IL-4 [38]. Yet on the contrary, in some children receiving probiotics, reduced IL-10 responsiveness to house dust mites allergens was observed [39]. In a study, the effects of feeding Lctbs F19 were evaluated during weaning on the incidence of eczema and Th1/Th2 balance. In a double-blind, placebo-controlled randomized intervention trial, infants were fed cereals with (n:89) or without Lctbs F19 (n:90) from 4 to 13 months of age.

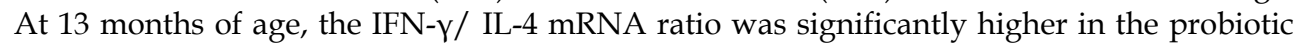
compared with the placebo group. The higher Th1/Th2 ratio in the probiotic compared with the placebo group suggests enhancing effects of Lctbs F19 on the T cell-mediated immune response. And probiotics also increased Th1 cytokines and inhibited allergen-induced IgE and Th2 cytokines in some atopic children $[40,41]$.

In a mouse model, effect of oral probiotics administration, including Bfdbm lactis/bifidum and Lctbs acidophilus, on mice with ovalbumin (OVA)-induced food allergy was studied. The mice treated with probiotics suppressed production of the OVA-specific IgE, IgG1, and IgA. Additionally, the level of IL-4 was significantly lower, and the levels of INF- $\gamma$ and IL-10 were significantly higher in the mice treated with probiotics than that in the nontreated mice [42]. Another murine model showed that oral administration of an immunostimulatory DNA sequence from Bfdbm longum suppressed Th2 immune responses in mice and inhibited IgE production in vitro [43]. A final study showed that the administration of either Bfdbm lactis Bb-12 or LGG suppressed antigen-specific IgE production too [44].

A decrease in the secretion of pro-inflammatory cytokines, IFN- $\gamma$, TNF- $\alpha$ and IL-12 has been demonstrated. Consistently, in an experimental study, probiotic supplementation decreased the severity of allergic skin responses in allergen-sensitized pigs with a corresponding increase in IFN- $\gamma$ expression [45]. However, the study by Rosenfeldt et al. demonstrated no significant changes in serum cytokines (IL-2, IL-4, IL-10 and IFN- $\gamma$ ) during 6 weeks of probiotic treatment [46]. Another study by Brouwer et al. showed no statistically significant effects of probiotic supplementation on cytokine production (IL-4, IL-5 and IFN- $\gamma$ ) as well [47]. These results differ from those of Pohjavuori et al, who were able to demonstrate an increase of IFN- $\gamma$ production in peripheral blood mononuclear cell in infants with AD treated with LGG instead of placebo [48]. Additionally, the improvement in AD severity of very young children with probiotic treatment was detected to be associated with significant 
increases in the capacity for Th1 IFN-ץ responses and altered responses to skin and enteric flora. This effect was still evident 2 months after the supplementation was ceased [49].

Reduction in serum soluble CD4 as a marker of T-cell activation described by Isolauri et al. They also found significant changes in indirect markers of allergic inflammation, such as sCD4 in the serum of infants with AD supplemented with Bfdbm lactis and LGG [50].

In a randomized controlled trial by Boyle et al showed that LGG treatment during pregnancy (prenatal) for the prevention of eczema was not associated with any change in cord blood immune markers such as TGF- $\beta$, IL-10, IL-12, IL-13, IFN- $\gamma$ and TNF- $\alpha$ as well as Dendritic and Treg cell numbers [51].

Twelve human studies were included in a review and $67 \%$ showed a positive association with TGF- $\beta 1$ or TGF- $\beta 2$ demonstrating protection against allergy-related outcomes in infancy and early childhood. High variability in concentrations of TGF- $\beta$ was noted between and within studies, some of it explained by maternal history of atopy or by consumption of probiotics. Human milk TGF- $\beta$ appears to be essential in developing and maintaining appropriate immune responses in infants and may provide protection against adverse immunological outcomes, corroborating findings from experimental animal studies. In a study, aim was to evaluate the effect of probiotic supplementation on the immunological composition of breast milk and colostrum in relation to sensitization and eczema in the babies. Total IgA, secretory IgA, TGF- $\beta 1$, TGF- $\beta 2$, IL-10, TNF- $\alpha$, and soluble CD14 were analyzed in colostrum and mature milk obtained from women treated with probiotics from gestational week 36 until delivery. The total IgA, secretory IgA, TGF- $\beta 1$, TNF-a, and sCD14 in breast milk were not affected by the intake of probiotics. Supplementation of probiotics during pregnancy was associated with low levels of TGF- $\beta 2$ and slightly increased levels of IL-10 in colostrum. Infants receiving breast milk with low levels of TGF- $\beta 2$ were less likely to become sensitized and possibly less IgE-associated eczema in breast-fed infants during their first $2 \mathrm{yr}$ of life [52]. However, another trial by Boyle et al showed that LGG treatment during pregnancy (prenatal) for the prevention of eczema was associated with decreased breast milk soluble CD14 and IgA levels, not TGF- $\beta$ [51]. The difference between these studies looks probiotic species, which may affect the immunological composition of breast milk.

\subsubsection{Anti-inflammatory effects: Their effects on serum inflammatory parameters}

The anti-inflammatory effect of probiotics has been attributed to increased production of IL10 by immune cells in the lamina propria, Peyer's patches and the spleen of treated animals [35-38]. Oral administration of LGG resulted in elevated IL-10 concentrations in atopic children, indicating that specific probiotics may have anti-inflammatory effects in vivo and possible enhancing regulatory or tolerance-inducing mechanisms as well. A review of the evidence from randomized controlled trials by Betsi et al about probiotics for the treatment or prevention of $\mathrm{AD}$ : the results of 13 relevant randomized (placebo)-controlled trials (RCTs) were reviewed: 10 of which evaluated probiotics as treatment and 3 for prevention of $\mathrm{AD}$. In four of these six RCTs, clinical improvement was associated with a change in some inflammatory markers [53]. Another randomized, double-blind, placebo-controlled study conducted by Brouwer et al showed no statistically significant effects of probiotic supplementation on inflammatory parameters [47].

Some probiotics have been reported to reduce proinflammatory cytokines through Th17 cells. Suppression of this newly discovered subset of $\mathrm{T}$ cells by probiotics might explain effects observed in different experimental models that all involve inflammatory responses. For instance, Lctb casei suppressed inflammation reducing proinflammatory cytokines released from Th17 cells [54]. Also, in a study administration of the probiotics mixture 
(Lctbs acidophilus, Lctbs casei, Lctbs reuteri, Bfdbm bifidum, and Streptococcus thermophilus) induced both T-cell and B-cell hyporesponsiveness and down-regulated Th1, Th2, and Th17 cytokines [55].

A study by Woo et al evaluated the effect of Lctbs sakei supplementation in children with atopic eczema-dermatitis syndrome. In this study, compared with placebo, probiotic administration was associated with lower pretreatment-adjusted serum levels of chemokines such as CCL17 and CCL27, which were significantly correlated with SCORAD total score [56]. Probiotic-induced chronic low-grade inflammation characterized by elevation of CRP, IgE, IgA, and IL-10 was shown in some studies, the changes typically observed in helminth infection-associated induction of regulatory mechanisms. The association of increased CRP with a decreased risk of eczema at 2 years of age in allergy-prone children supports the view that chronic, low-grade inflammation protects from eczema. The findings emphasize the role of chronic microbial exposure as an immune modulator protecting from allergy [57].

A study by Rosenfeldt et al, 2 probiotic Lctbs strains (lyophilized Lctbs rhamnosus 190702 and Lctbs reuteri DSM 122460) were given in combination for 6 weeks to 1- to 13-year-old children with AD. During active treatment, serum eosinophil cationic protein (ECP) levels significantly decreased. A combination of Lctbs rhamnosus and Lctbs reuteri was beneficial in the management of $\mathrm{AD}$ and the effect was more pronounced in atopic eczema patients [46]. Another study was conducted by Brouwer et al showed, during Lctbs species supplementation, a moderate but significant reduction in soluble ECP levels was found. $\mathrm{ECP}$, a cytotoxic protein released from activated eosinophils, has been used to monitor disease activity in AD. Thus SECP might be a more sensitive marker in acute exacerbations of the eczema than a marker of disease activity per se [47]. Although this study by Brouwer et al revealed no statistically significant effects of probiotic supplementation on eosinophil protein $X(E P X)$ in urine, Isolauri et al found significant changes in EPX in the urine of infants supplemented with Bfdbm lactis and LGG [15].

\subsubsection{Development of tolerogenic Dendritic cells}

Selected species of the Bfdbm genus were demonstrated to prime in vitro cultured neonatal Dendritic cell (DC)s to polarize $\mathrm{T}$ cell responses and may therefore be used as candidates in primary prevention of allergic diseases. Bfdbm bifidum was found to be most potent polarizer in vitro-cultured DCs to drive Th1-cell responses involving increased IFN- $\gamma$ producing $\mathrm{T}$ cells concomitant with reduction of IL-4-producing T-cells [58]. In addition, T-cells stimulated by Bfdbm bifidum matured DCs as producers of more IL-10 [59]. Moreover, Lctbs rhamnosus, member of another genus of probiotic bacteria, modulates DC function to induce a novel form of T-cell hyporesponsiveness [60]. Lctbs reuteri/casei have been also shown to prime monocytederived DCs through the C-type lectin DC-specific intercellular adhesion molecule 3-grabbing non-integrin (DC-SIGN) to drive the development of Treg cells [61]. These Treg cells produce increased levels of IL-10 and are capable of inhibiting the proliferation of bystander T cells. This study suggests that the targeting of DC-SIGN by certain probiotic bacteria might explain their beneficial effect in the treatment of a number of inflammatory diseases, including AD.

\subsubsection{Immunoregulation by T regulatory (Treg) cells}

As mentioned earlier, Lctbs reuteri / casei have been also shown to prime monocyte-derived DCs through the DC-SIGN to drive the development of Treg cells [61]. And the probiotic combinations are alleged to cause a paradoxic Th2 stimulation and to induce chronic low- 
grade inflammation, practically the same as in chronic and balanced helminth infection, which is associated with activation of Treg cells suppressing allergic inflammation. Since the colonization is yet transient, the induction of Treg cells is not permanent. Thus when these immunologic effects no longer operate, the clinical effect is simultaneously lost. For instance, when helminth infections are treated, the prevalence of allergic sensitization increases rapidly. This is a plausible explanation for the fading probiotic effect as well [57].

Recent studies also provided evidence that one effect of probiotics may involve induction of differentiation of IL-10-dependent, TGF- $\beta$-bearing Tregs. In a food allergy mouse model, oral administration of Bfdbm bifidum and Lctbs acidophilus suppressed OVA-specific IgE production, which was caused by inducing Treg -associated TGF- $\beta$ production [62]. Another study demonstrated that neonatal application of probiotic bacteria inhibits subsequent allergic sensitization and airway disease in a murine model of asthma by induction of Treg cells and TGF- $\beta$ production [63].

Generation of CD4+/Foxp3+ Treg cells by probiotics administration suppresses immune and allergic disorders. Recently, two studies reported that oral administration of a certain probiotic strain could increase Foxp3+ Tregs [55]. It is known that the lower percentage of epidermal or dermal Foxp3+ cells in eczematous dermatitis might contribute to their pathogenesis [64]. In a recent study, a mixture of probiotics (Lctbs acidophilus, Lctbs casei, Lctbs reuteri, Bfdbm bifidium, and Streptococcus thermophilus) was identified that upregulates $\mathrm{CD} 4+$ /Foxp3+ Treg cells. Administration of the probiotics mixture induced both T-cell and B-cell hyporesponsiveness and down-regulated Th1, Th2, and Th17 cytokines $[55,65]$. It also induced generation of CD4+/Foxp3+ Tregs from the CD4+/25- population and increased the suppressor activity of naturally occurring CD4+/25+ Tregs. Conversion of T cells into Foxp3+ Tregs is directly mediated by regulatory DCs that express high levels of IL-10 and TGF- $\beta$. In a murine AD model, treatment with this probiotic mixture significantly inhibited the clinical symptoms of AD progression by reducing IgE levels [total and specific IgE levels], infiltrated lymphocytes and granulocytes, and levels of AD-associated cytokines [55]. Lctbs casei treatment enhanced the frequency of FoxP3(+) Treg in the skin and increased the production of IL-10 by CD4+/25+ Treg cells in skin draining lymph nodes of hapten-sensitized mice. These data demonstrate that orally administered Lctbs casei (DN114 001) efficiently alleviate $\mathrm{T}$ cell-mediated skin inflammation without causing immune suppression, via mechanisms that include control of CD8+ effector $\mathrm{T}$ cells and involve regulatory $\mathrm{CD} 4+\mathrm{T}$ cells. Lctbs casei may thus represent a probiotic of potential interest for immunomodulation of $\mathrm{T}$ cell-mediated allergic skin diseases in human [66]. However, another study showed that Foxp3 mRNA expression at 6 months of age is higher in infants having $\mathrm{AD}$, but it is not affected by giving probiotics from birth [67].

\subsubsection{Lymphocyte subpopulations}

Several studies reveal that the probiotics differently modulate peripheral blood immune parameters in healthy subjects and patients with AD.

Gerasimov et al conducted a study to assess the clinical efficacy and impact of Lctbs acidophilus DDS-1, Bfdbm lactis UABLA-12 with fructo-oligosaccharide on peripheral blood lymphocyte subsets in preschool children with moderate-to-severe AD. The percentage of CD4, and the percentage and absolute count of CD25 decreased, and the percentage and absolute count of CD8 increased in the probiotic group at week 8, compared with placebo $(\mathrm{p}:<0.007)$. They found a significant correlation between CD4 percentage, CD25 percentage, 
CD25 absolute count, and SCORAD values in the probiotic group at week 8 . The administration of a probiotic mixture and fructo-oligosaccharide was correlated with significant clinical improvement in children with $\mathrm{AD}$, with corresponding lymphocyte subpopulation changes in peripheral blood [68].

However, in another study major lymphocyte subsets were not affected by the probiotic intervention. The expression of $\mathrm{CD} 4+/ 25+\mathrm{T}$ cells was similar in healthy subjects and AD patients, whereas CD4+/54+ decreased significantly in patients with $\mathrm{AD}$ and remained uninfluenced in healthy subjects. The purpose of a study by Roessler et al was to elucidate the influence of a probiotic drink containing a combination of the probiotics Lctbs paracasei Lpc-37, Lctbs acidophilus 74-2 and Bfdbm animalis subsp. lactis DGCC 420 (Bfdbm lactis 420 ) in healthy volunteers and in patients with $\mathrm{AD}$ on clinical and immunological parameters and their detection in feces. In a double-blind, randomized cross-over study was conducted in 15 healthy adults and 15 patients with AD. The probiotic product or placebo was given over 2 months. In AD patients, the SCORAD tended to decrease by $15.5 \%$ (P:0.08). However, CD57+ increased significantly in healthy subjects after probiotic intake and was not changed in patients [69].

\subsubsection{Toll-like receptor (TLR) stimulation}

A number of experiments indicate that infectious agents can promote protection from ADs through mechanisms independent of their constitutive antigens, leading to stimulation of non-antigen specific receptors such as TLRs. A family of pattern recognition receptors such as TLRs on gut lymphoid and epithelial cells mediates innate immune responses to bacterial molecular patterns and, thereby, orchestrates acquired immunity. The transient protection offered by probiotics against IgE-associated allergic diseases is based on stimulation of TLRs, which produce mediators such as IL-6; these further induce IgA differentiation from naive B cells. Both these events were shown to to occur after probiotic administration to infants with eczema, as well as in infants who showed increased levels of serum CRP, IL-10, and IgE at age 6 months.

Similarly, TLR stimulation was also thought to happen after probiotic administration in infants with eczema who showed increased levels of serum CRP, IL-10, and IgE [57]. This probiotic-induced low-grade inflammation was characterized by elevation of CRP, IgE, IgA, and IL-10, the changes typically observed in helminth infection-associated induction of regulatory mechanisms. Moreover, the association of increased CRP with a decreased risk of eczema at 2 years of age in allergy-prone children supports the view that chronic, low-grade inflammation protects from eczema. The findings emphasize the role of chronic microbial exposure as an immune modulator protecting from allergy thru activation of Treg cells. Consistently, lactic acid bacteria species such as Bfdbm bifidum / infantis and Lctbs salivarius were shown to be capable of activating TLR-2 [70]. Oral administration of Lctbs reuteri attenuated major characteristics of an asthmatic response, including airway eosinophilia, local cytokine responses, and hyperresponsiveness to methacholine. This effect of Lctbs reuteri on the allergic airway response was found to be dependent on TLR-9 [71]. In summary, local influences of probiotics potentially include reduction of gut permeability and systemic penetration of antigens, increased local IgA production, and alteration of local inflammation or tolerance induction. Some possible systemic effects consist of antiinflammatory effects mediated by TLRs, Th1 skewing of responses to allergens, and activation of tolerogenic DCs, in addition to Treg cell production. [The various effects of different probiotic strains in atopic diseases as well as in AD are summarized in table 1]. 


\begin{tabular}{|c|c|c|c|}
\hline References & Probiotic Strain & Effect of probiotic & Outcome \\
\hline & & Maturing Gut Barrier & \\
\hline Sudo et al 27 & Bfdbm & Oral tolerance & $\uparrow$ \\
\hline $\begin{array}{l}\text { Isolauri et al } \\
15,29,50,76\end{array}$ & LGG & Fecal IgA levels & $\uparrow$ \\
\hline $\begin{array}{l}\text { Isolauri et al } \\
15,29,50,76\end{array}$ & $\begin{array}{l}\text { Lctbs rhamnosus GG } \\
\text { (LGG) }\end{array}$ & Gut-stabilizing effect & $\uparrow$ \\
\hline Malin et al 31 & LGG & Gut defense & $\uparrow$ \\
\hline \multirow[t]{2}{*}{ Kaila et al 33} & Lctbs & Intestinal permeability & $\downarrow$ \\
\hline & & Immunomodulation & \\
\hline Niers et al $37,58,82$ & $\begin{array}{l}\text { Bfdbm bifidum / } \\
\text { infantis; Lctbs lactis }\end{array}$ & Th2 Cytokines & $\downarrow$ \\
\hline Niers et al 37,58,82 & $\begin{array}{l}\text { Bfdbm bifidum / } \\
\text { infantis; Lctbs lactis }\end{array}$ & IL-10 Production & $\uparrow$ \\
\hline Maassen et al 38,105 & Lctbs casei & IL-10 Production & $\uparrow$ \\
\hline Maassen et al 38,105 & Lctbs reuteri & Th1 Cytokines & $\uparrow$ \\
\hline Maassen et al 38,105 & Lctbs casei & IL-4 Production & $\uparrow$ \\
\hline Kim et al 42,62,83 & $\begin{array}{l}\text { Bfdbm lactis/ bifidum; } \\
\text { Lctbs acidophilus }\end{array}$ & IL-10 Production & $\uparrow$ \\
\hline Kim et al 42,62,83 & $\begin{array}{l}\text { Bfdbm lactis/ bifidum; } \\
\text { Lctbs acidophilus }\end{array}$ & IL-4 Production & $\downarrow$ \\
\hline Kim et al 42,62,83 & $\begin{array}{l}\text { Bfdbm lactis/ bifidum; } \\
\text { Lctbs acidophilus }\end{array}$ & IFN- $\gamma$ Production & $\uparrow$ \\
\hline Kim et al 42,62,83 & $\begin{array}{l}\text { Bfdbm lactis/ bifidum; } \\
\text { Lctbs acidophilus }\end{array}$ & IgE Production & $\downarrow$ \\
\hline Takahashi 43 & Bfdbm longum & Th2 Cytokines & $\downarrow$ \\
\hline Takahashi 43 & Bfdbm longum & IgE Production & $\downarrow$ \\
\hline Sistek et al 41 & $\begin{array}{l}\text { Lctbs rhamnosus GG } \\
\text { (LGG) }\end{array}$ & IL-10 Production & $\uparrow$ \\
\hline Kruisselbrink et al 39 & Lctbs plantarum & IL-10 Production & $\downarrow$ \\
\hline \multirow[t]{2}{*}{ Hart et al 59} & Bfdbm bifidum & IL-10 Production & $\uparrow$ \\
\hline & & Th1/Th2 balance & \\
\hline Niers et al 58 & Bfdbm bifidum & $\begin{array}{l}\text { Most potent Dendritic cell } \\
\text { polarizer in vitro }\end{array}$ & $\uparrow$ \\
\hline Hart et al 59 & Bfdbm bifidum & $\begin{array}{l}\text { Human Dendritic cell } \\
\text { phenotype modulator }\end{array}$ & $\uparrow$ \\
\hline Braat et al 60 & Lctbs rhamnosus & $\begin{array}{l}\text { Dendritic cell function } \\
\text { modulator }\end{array}$ & $\uparrow$ \\
\hline \multirow[t]{2}{*}{ Smits et al 61} & Lctbs reuteri / casei & $\begin{array}{l}\text { Prime monocyte-derived } \\
\text { Dendritic cell }\end{array}$ & $\uparrow$ \\
\hline & & $\begin{array}{l}\text { Serum Inflammatory } \\
\text { Parameters }\end{array}$ & \\
\hline
\end{tabular}




\begin{tabular}{|c|c|c|c|}
\hline References & Probiotic Strain & Effect of probiotic & Outcome \\
\hline Maassen et al 38,105 & Lctbs reuteri & Immunomodulation & $\uparrow$ \\
\hline \multirow[t]{2}{*}{ Sistek et al 41} & $\begin{array}{l}\text { Lctbs rhamnosus GG } \\
\text { (LGG) }\end{array}$ & Immunomodulation & $\downarrow$ \\
\hline & & $\begin{array}{l}\text { Development of Tolerogenic } \\
\text { Dendritic Cells }\end{array}$ & \\
\hline Niers et al $37,58,82$ & Bfdbm & Prime neonatal Dendritic cell & $\uparrow$ \\
\hline Braat et al 60 & Lctbs rhamnosus & $\begin{array}{l}\text { Modulates Dendritic cell } \\
\text { function }\end{array}$ & $\uparrow$ \\
\hline \multirow[t]{2}{*}{ Smits et al 61} & Lctbs reuteri / casei & $\begin{array}{l}\text { Prime monocyte-derived } \\
\text { Dendritic cell }\end{array}$ & $\uparrow$ \\
\hline & & Toll-like Receptor Stimulation & \\
\hline Hoarau et al 70 & $\begin{array}{l}\text { Bfdbm bifidum / } \\
\text { infantis; Lctbs } \\
\text { salivarius }\end{array}$ & Activate TLR-2 & $\uparrow$ \\
\hline \multirow[t]{2}{*}{ Forsythe et al 71} & Lctbs reuteri & Activate TLR-9 & $\uparrow$ \\
\hline & & T-regulatory Cell Production & \\
\hline Smits et al 61 & Lctbs reuteri / casei & $\begin{array}{l}\text { Prime monocyte-derived } \\
\text { Dendritic cell }\end{array}$ & $\uparrow$ \\
\hline Kim et al $42,62,83$ & $\begin{array}{l}\text { Bfdbm bifidum; Lctbs } \\
\text { acidophilus }\end{array}$ & TGF- $\beta$ production & $\uparrow$ \\
\hline \multirow[t]{2}{*}{ Feleszko 63} & $\begin{array}{l}\text { LGG, Bfdbm lactis (Bb- } \\
12)\end{array}$ & TGF- $\beta$ production & $\uparrow$ \\
\hline & & T-cell Hyporesponsiveness & \\
\hline Kruisselbrink et al 39 & Lctbs plantarum & $\begin{array}{l}\text { Inhibits specific T-cell } \\
\text { responses }\end{array}$ & $\uparrow$ \\
\hline Braat et al 60 & Lctbs rhamnosus & $\begin{array}{l}\text { Modulates Dendritic cell } \\
\text { function }\end{array}$ & $\uparrow$ \\
\hline
\end{tabular}

Abbreviations: Lctbs = Lactobacillus; Bfdbm = Bifidobacterium; LGG= Lactobacillus rhamnosus GG; $\uparrow=$ increase in symptoms or negative effect; $\downarrow=$ decrease in symptoms or positive effect; $\leftrightarrow=$ No change in symptoms or no effect

Table 1. Various mechanisms for effects of probiotic strains in atopic disorders including eczema are shown from experimental (animal) and clinical (human) studies referred in the chapter text.

\section{The role of probiotics in the prevention and treatment of $A D$}

The increased prevalence of atopic diseases is nowadays defined as an epidemic. AD is known as the earliest of these conditions, might act as an indicator for the development of IgE-mediated atopic manifestations. Thus, being aware of possible measures, such as probiotic use, to prevent and/or heal atopic disease is essential for the practicing allergist. Here, their role in the prevention and therapy of $\mathrm{AD}$ under the recent literature gathered from Medline and Pubmed are discussed. The various effects of different probiotic strains in AD are summarized in table 2. 


\begin{tabular}{|c|c|c|c|}
\hline References & Probiotic Species & Type of Atopic Dermattis & Outcome \\
\hline & & $\begin{array}{c}\text { Atopic (IgE-associated) } \\
\text { Eczema }\end{array}$ & \\
\hline $\begin{array}{l}\text { Isolauri et al } \\
15,29,50,76\end{array}$ & Bfdbm or Lctbs & Food (cow's milk) Allergy & $\downarrow$ \\
\hline Wickens et al 81 & Lctbs rhamnosus & IgE-associated eczema & $\downarrow$ \\
\hline Viljanen et al 28,72 & LGG & $\begin{array}{l}\text { Atopic eczema/dermatitis } \\
\text { syndrome }\end{array}$ & $\downarrow$ \\
\hline Sistek et al 41 & $\begin{array}{l}\text { Lctbs rhamnosus + Bfdbm } \\
\text { lactis }\end{array}$ & $\begin{array}{l}\text { Eczema , food-sensitized } \\
\text { atopy }\end{array}$ & $\downarrow$ \\
\hline Kuitunen et al 74 & $\begin{array}{l}\text { Lctbs+ Bfdbm+ } \\
\text { Propionibacteria }\end{array}$ & IgE-associated allergy & $\downarrow$ \\
\hline Majamaa et al 15 & LGG & Food-sensitized eczema & $\downarrow$ \\
\hline Rosenfeldt et al 49 & $\begin{array}{l}\text { Lctbs rhamnosus + Lctbs } \\
\text { reuteri }\end{array}$ & Atopic eczema & $\downarrow$ \\
\hline $\begin{array}{l}\text { Kukkonen et al 73, } \\
108\end{array}$ & $\begin{array}{l}\text { Mix (LGG, Lctbs rhamnosus } \\
\text { LC705, Bfdbm breve, } \\
\text { Propionibacterium) } \\
\end{array}$ & Atopic eczema & $\downarrow$ \\
\hline \multirow[t]{2}{*}{ Abrahamsson et al 75} & Lctbs reuteri ATCC 55730 & Atopic eczema & $\downarrow$ \\
\hline & & Non-atopic Eczema & \\
\hline Kalliomäki et al 16 & LGG & Atopic dermatitis & $\downarrow$ \\
\hline Woo et al 56 & Lctbs sakei & Atopic dermatitis & $\downarrow$ \\
\hline Weston et al 78 & Lctbs fermentum & Atopic dermatitis & $\downarrow$ \\
\hline Hoang et al 79 & Lctbs rhamnosus & Atopic dermatitis & $\downarrow$ \\
\hline Hattori et al 80 & Bfdbm breve & Atopic dermatitis & $\downarrow$ \\
\hline Wickens et al 81 & $\begin{array}{l}\text { Lctbs rhamnosus, Bfdbm } \\
\text { animalis (Bb-12) }\end{array}$ & Atopic dermatitis & $\downarrow$ \\
\hline Marschan et al 57 & $\begin{array}{l}\text { Mix (LGG, Lctbs rhamnosus } \\
\text { LC705, Bfdbm breve, } \\
\text { Propionibacterium) }\end{array}$ & Atopic dermatitis & $\downarrow$ \\
\hline Niers et al $37,58,82$ & $\begin{array}{l}\text { Bfdbm bifidum, Bfdbm } \\
\text { lactis, Lactococcus lactis }\end{array}$ & Atopic dermatitis & $\downarrow$ \\
\hline Kim et al 42,62,83 & $\begin{array}{l}\text { Bfdbm bifidum, Bfdbm } \\
\text { lactis, Lctbs acidophilus }\end{array}$ & Atopic dermatitis & $\downarrow$ \\
\hline Dotterud et al 84 & $\begin{array}{l}\text { LGG, Lctbs acidophilus, } \\
\text { Bfdbm animalis (Bb-12) }\end{array}$ & Atopic dermatitis & $\downarrow$ \\
\hline Böttcher et al 52 & Lctbs reuteri & $\begin{array}{l}\text { Atopic dermatitis } \\
\text { (sensitization) }\end{array}$ & $\downarrow$ \\
\hline West et al 40 & Lctbs casei F19 & Atopic dermatitis & $\downarrow$ \\
\hline $\begin{array}{l}\text { Lodinova-Zadnikova } \\
\text { et al } 85\end{array}$ & Escherichia coli & $\begin{array}{l}\text { Atopic dermatitis (IgE } \\
\text { allergies) }\end{array}$ & $\downarrow$ \\
\hline Gerasimov et al 68 & $\begin{array}{l}\text { Lctbs acidophilus, Bfdbm } \\
\text { lactis }\end{array}$ & Atopic dermatitis & $\downarrow$ \\
\hline
\end{tabular}




\begin{tabular}{||l|l|l|c||}
\hline \multicolumn{1}{|c|}{ References } & \multicolumn{1}{|c|}{ Probiotic Species } & Type of Atopic Dermattis & Outcome \\
\hline & & Eczema (atopic dermatitis) & \\
\hline Kopp et al 88 & LGG & $\begin{array}{l}\text { Atopic dermatitis } \\
\text { (wheezing) }\end{array}$ & $\leftrightarrow,(\uparrow)$ \\
\hline Taylor et al 87 & LGG or Lctbs acidophilus & $\begin{array}{l}\text { Atopic dermatitis (cow's } \\
\text { milk allergy) }\end{array}$ & $\leftrightarrow,(\uparrow)$ \\
\hline Boyle RJ et al 51 & LGG & Atopic dermatitis & $\leftrightarrow$ \\
\hline Gruber et al 89 & LGG & Atopic dermatitis & $\leftrightarrow$ \\
\hline Soh et al 91 & $\begin{array}{l}\text { Bfdbm longum + Lctbcs } \\
\text { rhamnosus }\end{array}$ & $\begin{array}{l}\text { Eczema and atopic } \\
\text { sensitization }\end{array}$ & $\leftrightarrow$ \\
\hline Lee et al 95 & Various & Atopic dermatitis & $\leftrightarrow$ \\
\hline Brouwer et al 47 & Lctbs rhamnosus & Atopic dermatitis & $\leftrightarrow$ \\
\hline Kuitunen et al 74 & $\begin{array}{l}\text { Lctbs+ Bfdbm }+ \\
\text { Propionibacteria }\end{array}$ & Atopic dermatitis & $\leftrightarrow$ \\
\hline Fölster-Holst et al 90 & LGG & Atopic dermatitis & $\leftrightarrow$ \\
\hline
\end{tabular}

Abbreviations: Lctbs = Lactobacillus; Bfdbm = Bifidobacterium; LGG= Lactobacillus rhamnosus GG; $\uparrow=$ increase in symptoms or negative effect; $\downarrow=$ decrease in symptoms or positive effect; $\leftrightarrow=$ No change in symptoms or no effect

Table 2. The various effects of different probiotic strains, referred in the chapter text, in atopic and non-atopic eczema are shown.

Any difference for IgE-sensitized (atopic) vs. non-IgE-sensitized (non-atopic) eczema groups?

A number of studies could only relate probiotic benefits to a certain subset of AD patients. In support of the efficacy of probiotics in IgE-sensitized children, some other studies also demonstrated comparable results as well. In brief: treatment with Lctbs rhamnosus for the first 2 years of life was associated with a significant reduction in the prevalence of any IgEassociated eczema by about a half [16]. Another study demonstrated that LGG alleviated atopic eczema/dermatitis syndrome symptoms in IgE-sensitized infants [28]. In foodsensitized atopic children, the efficacy of the probiotics such as Lctbs rhamnosus and Bfdbm lactis was demonstrated too [40]. This effect was more pronounced in patients with a positive skin prick test and increased IgE levels.

Yet, some other studies failed to demonstrate that the severity and frequency of AD were decreased with the supplementation of probiotics, regardless of their IgE sensitization status. For instance; Boyle et al and others could not show any effect even for LGG in infants with AD [51]. A few meta-analyses also could not confirm that IgE sensitization was indeed a factor in determining the efficacy of probiotics in atopic children. However, the heterogeneity between studies may be attributable to probiotic strain-specific effects and other factors as well, meaning that some probiotic strains may still have a therapeutic role in eczema $[13,14]$.

\subsection{IgE-sensitized (atopic) eczema therapy and prevention}

Recently published one of the largest studies by Viljanen et al to date compared LGG or a probiotic mix (LGG, Lctbs rhamnosus LC705, Bfdbm breve Bb99, and Propionibacterium freudenreichii ssp. shermanii JS) with placebo. In this study, 230 Finnish children with AD were treated for 4 weeks with LGG, a mixture of four probiotic strains or placebo. With 
supplementation with probiotics (LGG), Viljanen et al found significant improvement on the SCORAD index only in "IgE-sensitized -cow's milk -allergic- infants of the atopic eczema/dermatitis syndrome (AEDS). Only in the subgroup of IgE-sensitized children, did the LGG group show a greater reduction in SCORAD than the placebo group but this effect could have been due to a higher baseline score in this subgroup. There was no difference between the groups at the end of 4-week therapy and 4 weeks after therapy was discontinued. Contrary to what would be expected, improvement was seen 4 weeks after discontinuation of therapy rather than during treatment [28,72]. Rosenfeldt et al from Denmark in a study, 2 lyophilized probiotic Lctbs strains (lyophilized Lctbs rhamnosus 19070-2 and Lctbs reuteri DSM 122460) were given in combination for 6 weeks to 1- to 13year-old (mean age, 5.2 years) children with AD. This study used 2 different Lctbs species in older children. A combination of these was beneficial in the management of AD. Statistically significant improvement in SCORAD score was seen only in a subset of children with positive skin prick test results and elevated IgE levels [46]. Another study by Sistek et al showed the efficacy of the probiotics Lctbs rhamnosus and Bfdbm lactis in food-sensitized children [41].

A study by Finnish group used the same probiotic mixture with prebiotic. Kukkonen et al in a trial using probiotic mix (Lctbs rhamnosus GG, Lctbs rhamnosus LC705, Bfdbm breve Bb99; and Propionibacterium freudenreichii ssp. shermanii JS) and prebiotic galactooligosaccharides demonstrated that the prevention of atopic eczema in high-risk Finnish infants is possible by modulating the infant's gut microbiota with probiotics and prebiotics. Probiotic treatment compared with placebo reduced IgE-associated (atopic) diseases. Probiotic treatment also reduced eczema and atopic eczema [73].

In 2009, in a study by Kuitunen et al 1223 Finnish mothers were randomized with infants at high risk for allergy to receive the same probiotic mixture (2 Lactobacilli, Bifidobacteria, and propionibacteria) or placebo during the last month of pregnancy and their infants to receive it from birth until age 6 months. Infants also received a prebiotic galacto-oligosaccharide or placebo. At 5 years, the cumulative incidence of allergic diseases (eczema, food allergy, allergic rhinitis, and asthma) and IgE sensitization were evaluated. Frequencies of allergic and IgE-associated allergic disease and sensitization in the probiotic and placebo groups were similar. However, less IgE-associated allergic disease occurred in cesarean-delivered children receiving probiotics. No allergy-preventive effect that extended to age 5 years was achieved with perinatal supplementation of probiotic bacteria to high-risk mothers and children. It conferred protection only to cesarean-delivered children [74].

Similarly; Abrahamsson et al could not confirm a preventive effect of probiotics (Lctbs reuteri ATCC 55730) on infant eczema in a recently published study. However, he observed that the treated infants had less IgE-associated eczema at 2 years. Moreover, skin prick test reactivity was also less common in the treated group than in the placebo group, but this difference reached significance only for infants with allergic Swedish mothers [75].

In conclusion; all of these studies taken together demonstrate that probiotics are might not be effective and / or therapeutic for all children with AD, but offer benefit in a subset of IgEsensitized children.

\subsection{Non-IgE-sensitized (non-atopic) eczema therapy and prevention}

Until now, several clinical studies have been published that have focused on the use of probiotics for therapy and primary prevention of atopic diseases. To date, the results of at 
least 15 prospective preventive studies with different Lctbs or Bfdbm strains (or mixture) in children at high risk for allergic diseases have been published.

The first study in the literature by Isolauri et al analyzed a benefit of LGG in mild AD disease in 1997. They observed 27 exclusively breastfed infants (median age 4-6 months) with mild AD (median SCORAD score of 16), receiving extensively hydrolysed whey formula with (LGG or Bfdbm strain) or without probiotics (placebo) for 8 weeks. They showed a reduction in the SCORAD by 15 points (from 16 to 1 ) for the LGG and by 16 points (from 16 to 0 ) for the Bfdbm arm, as compared with a reduction of 2-6 points (from 16 to 134 ) in the placebo arm. However, one month after therapy, SCORAD scores were comparable with those of placebo. Therefore, the probiotic effect was limited to acceleration of improvement in infants with mild disease [15]. The same investigators subsequently published 2 additional studies. One of these studies compared LGG with Bfdbm lactis Bb12 , both of which showed a significant improvement in SCORAD score over placebo. However, after 6 months, the median SCORAD score was zero in all groups, again suggesting that the effect is limited to rapid initiation of improvement [76]. The other study underlined the importance of viability for probiotic species. The use of heat inactivated LGG resulted in adverse gastrointestinal symptoms with diarrhea, and study recruitment was halted. They concluded that supplementation of infant formulas with viable but not heatinactivated LGG was found to be a potential approach for the management of atopic eczema and cow's milk allergy [77].

In an earlier study by Viljanen et al probiotics have been suggested to be useful in children with AEDS. In 2010, a study by Woo et al was performed to assess the clinical effect of Lctbs sakei supplementation in children with AEDS. In this study, children aged 2 to 10 years with AEDS with a minimum SCORAD score of 25 were randomized to receive either daily Lctbs sakei KCTC 10755BP or daily placebo supplementation for 12 weeks. At week 12, SCORAD total scores adjusted by pretreatment values were lower after probiotic treatment than after placebo treatment. There was a 31\% improvement in mean disease activity with probiotic use compared with a $13 \%$ improvement with placebo use. Therefore significant differences in favor of probiotic treatment were also observed in proportions of patients achieving improvement of at least $30 \%$ and $50 \%$. Interestingly, clinical improvement in this study was not just observed in the subgroup of IgE-sensitized children, contrary to Viljanen et al study, and it was regardless of IgE sensitization [56]. Weston et al from Australia published their experience with using Lctbs fermentum VRI-003 PCC for 8 weeks in 53 infants with AD. After 16 weeks the probiotic group had significant reduction of SCORAD scores while the placebo group did not. Lctbs fermentum caused a significant reduction in SCORAD scores. Although the change in SCORAD score from baseline in the probiotic group was significant, the difference between the probiotic and placebo groups did not reach significance by week 16 [78]. In a study by Hoang et al, they followed 14 cases of pediatric patients (ages of 8 months to 64 months) with a history of resistant eczema for a period of at least 6 months. All of these children received Lctbs rhamnosus cell lysate daily as an immunobiotic supplement. The results of this open label non-randomized clinical observation showed a substantial improvement in quality of life, skin symptoms and day- and nighttime irritation scores in children with the supplementation of Lctbs rhamnosus lysate. There were no intolerance or adverse reactions observed in these children. Lctbs rhamnosus cell lysate may thus be used as a safe and effective immunobiotic for the treatment and prevention of childhood eczema [79]. Bfdbm breve has been reported by Hattori et al to improve 
cutaneous symptoms of AD patients. Fifteen children with $\mathrm{AD}$ who had Bfdbm-deficient microflora were selected for this study. Eight subjects in the Bifidobacteria -administered group were given oral administration of lyophilized Bfdbm breve M-16V strain. In the Bifidobacteria -administered group, the proportion of Bfdbm in the fecal microflora was increased and the proportion of aerobic bacteria was decreased after 1 month of administration. Furthermore, significant improvement of allergic symptoms (in cutaneous symptom and total allergic scores) was also observed in the Bifidobacteria -administered group. The tendency of allergic symptom improvement was remarkable compared with the control group; however there was no correlation between changes in fecal microflora and allergic symptoms [80].

The Finnish study of Kalliomäki et al was the first report to describe that the frequency of $\mathrm{AD}$ in the probiotic group was half that of the placebo. This hallmark study demonstrated that administration of LGG for 1 month before and 6 months after birth to their infants was associated with a significant reduction in the cumulative incidence of eczema during the first 7 year of life. The effect of probiotics on preventing AD has been demonstrated in infants of Finnish pregnant mothers with a strong family history of eczema, allergic rhinitis or asthma. The frequency of developing AD in the offspring was significantly reduced by 2 , 4 , and 7 years, by $50 \%, 44 \%$, and $36 \%$; respectively. But there were no preventive effects on atopic sensitization and onset of respiratory allergic diseases [16].

Wickens et al studied a differential effect of 2 probiotics in the prevention of eczema and atopy. Infants receiving Lctbs rhamnosus had a significantly reduced risk of eczema, compared with placebo, but this was not the case for B animalis subsp lactis. In a doubleblind, randomized placebo-controlled trial of infants at risk of allergic disease, pregnant women were randomized to take Lctbs rhamnosus HN001, Bfdbm animalis subsp lactis strain HN019 or placebo daily from 35 weeks gestation until 6 months if breastfeeding, and their infants were randomized to receive the same treatment from birth to 2 years (n:474). Infants receiving Lctbs rhamnosus had a significantly reduced risk of eczema compared with placebo, but this was not the case for Bfdbm animalis subsp lactis. There was no significant effect of Lctbs rhamnosus or Bfdbm animalis subsp lactis on atopy. Lctbs rhamnosus (71.5\%) was more likely than Bfdbm animalis subsp lactis (22.6\%) to be present in the feces at 3 months, although detection rates were similar by 24 months. The authors found out that supplementation with Lctbs rhamnosus, but not Bfdbm animalis subsp lactis, substantially reduced the cumulative prevalence of eczema, but not atopy, by 2 years [81].

In a randomized double-blind study by Marschan et al, probiotic bacteria (Lctbs rhamnosus GG (ATCC 53103), Lctbs rhamnosus LC705, Bfdbm breve Bb99, and Propionibacterium freudenreichii ssp. Shermanii JS) or placebo were given for 1 month before delivery to mothers and for 6 months to infants with a family history of allergy. Infants receiving probiotic bacteria had higher plasma levels of CRP, total IgA, total IgE, and IL-10 than infants in the placebo group. Increased plasma CRP level at age 6 months was associated with a decreased risk of eczema and with a decreased risk of allergic disease at age 2 years, when adjusted with probiotic use. The association of CRP with a decreased risk of eczema at 2 years of age in allergy-prone children supports the view that chronic, low-grade inflammation protects from eczema. Probiotic-induced low-grade inflammation was characterized by elevation of IgE, IgA, and IL-10, the changes typically observed in helminth infection-associated induction of regulatory mechanisms [57] (please see the section: mechanisms of probiotics`effects). 
In the PandA study of Niers et al administered a mixture of probiotic bacteria (Bfdbm bifidum W23, Bfdbm lactis W52, and Lactococcus lactis W58; Ecologic Panda) for 6 week prenatally to mothers of high-risk children and to their offspring for the first 12 months of life. Although cumulative incidence of atopic eczema and IgE levels were similar in both treated and placebo groups, the parental reported eczema was significantly lower during the first 3 months of life in infants receiving probiotics. This particular combination of probiotic bacteria showed a preventive effect on the incidence of eczema in high-risk children, which seems to be sustained during the first 2 years of life. In addition to previous studies, the preventive effect appeared to be established within the first 3 months of life in this study [82].

In a trial by Kim et al, 112 pregnant women with a family history of allergic diseases received a mixture of Bfdbm bifidum BGN4, Bfdbm lactis AD011, and Lctbs acidophilus AD031, starting at 4-8 wks before delivery and continuing until 6 months after delivery. The cumulative incidence of eczema during the first 12 months was reduced significantly in probiotic group; however, there was no difference in serum total $\operatorname{IgE}$ level or the sensitization against food allergens between the two groups. Prenatal and postnatal supplementation with a mixture of probiotics is an effective approach in preventing the development of eczema in infants at high risk of allergy during the first year of life [83].

In a randomized, double-blind trial by Dotterud et al, probiotics was given in pregnant women to prevent allergic disease. In this study children from a nonselected maternal population, women received probiotic milk or placebo from 36 weeks of gestation to 3 months postnatally during breastfeeding. The probiotic milk contained Lctbs rhamnosus GG, Lctbs acidophilus La-5 and Bfdbm animalis subsp. lactis Bb-12. At 2 years of age, all children were assessed for atopic sensitization, AD, asthma and allergic rhinoconjunctivitis. Probiotics given to nonselected mothers reduced the cumulative incidence of $A D$, but had no effect on asthma or atopic sensitization [84].

Böttcher et al's study demonstrated that Lctbs reuteri supplementation during pregnancy associated with reduced risk of sensitization during infancy. Swedish pregnant women were treated with Lctbs reuteri (n:54) or placebo (n:55) from gestational week 36 until delivery. The infants were followed prospectively for 2 years regarding development of eczema and sensitization as defined by a positive skin prick test and/or circulating allergen-specific IgE antibodies at 6, 12, and 24 months of age [52].

Of note, another recently published Swedish study demonstrated that administration of Lctbs casei F19 during weaning significantly reduced the incidence of eczema, indicating that proper timing of the probiotic intervention is a critical factor. This study also supports the notion that there is more than a single window of opportunity to manage allergic diseases. This study evaluated the effects of feeding with Lctbs F19 during weaning period on the incidence of eczema and Th1/Th2 balance. In this intervention trial by West et al, infants were fed cereals with (n:89) or without Lctbs F19 (n:90) from 4-13 months of age. The cumulative incidence of eczema at 13 months was $11 \%$ and $22 \%$ in the probiotic and placebo groups, respectively $(\mathrm{p}:<0.05)$. At 13 months of age, the IFN- $\gamma /$ IL-4 mRNA ratio was significantly higher in the probiotic compared with the placebo group. The higher Th1/Th2 ratio in the probiotic compared with the placebo group suggests enhancing effects of Lctbs F19 on the T cell-mediated immune response. In contrast, there were no differences between groups in serum IgE concentrations. As a result, feeding Lctbs F19 during weaning could be an effective tool in the prevention of early manifestation of allergy such as eczema [40]. 
Oral administration of probiotic Escherichia coli after birth in the early postnatal period by Lodinova-Zadnikova et al reduced frequency of serum specific IgE allergies later in life (after 10 and 20 years) [85].

Gerasimov et al conducted a study to assess the clinical efficacy and impact of Lctbs acidophilus DDS-1, Bfdbm lactis UABLA-12 with fructo-oligosaccharide on peripheral blood lymphocyte subsets in preschool children with moderate-to-severe AD. In a randomized, double-blind, placebo-controlled, prospective trial of 90 children aged 1-3 years with moderate-to-severe $\mathrm{AD}$ who were treated with a mixture of probiotics with fructooligosaccharide for 8 weeks versus placebo. At the final visit, the percentage significant decrease in SCORAD was $33.7 \%$ in the probiotic group compared with $19.4 \%$ in the placebo group. Children receiving probiotic showed a greater decrease in the mean SCORAD score than did children from the placebo group at week 8 . The administration of a probiotic mixture and fructo-oligosaccharide was associated with significant clinical improvement in children with AD, with corresponding lymphocyte subset changes in peripheral blood [68]. In conclusion; here probiotics were more likely to be effective in treating moderately severe $\mathrm{AD}$ as well as mild atopic disease. Although not every study result above was significant, the effect of probiotics did not seem to be greater just in the IgE-sensitized group than in the non-IgE-sensitized group. Nevertheless, there have been several reports in the literature showing no effect of probiotics, which are being discussed the section below.

\subsection{No therapeutic or preventive effect of probiotics in AD regardless of $\lg E$ sensitization}

It is striking that the proportion of children with $\mathrm{AD}$ and allergic sensitization such as in the study of Taylor and Huurre et al was significantly higher in the probiotic group [86]. In Taylor et al's trial probiotic supplementation postnatally failed to reduce the risk of AD and increased the risk of allergen sensitization in high-risk children. Newborns of women with allergy (n:231) received either Lctbs acidophilus (LAVRI-A1) or placebo daily for the first 6 months of life. Children were assessed for AD and other symptoms at 6 and 12 months and had allergen skin prick tests at 12 months of age. At 6 and 12 months, AD rates were similar in the probiotic and placebo groups. At 12 months, the rate of sensitization was significantly higher in the probiotic group. The presence of culturable Lactobacilli or Bfdbm in stools in the first month of life was not associated with the risk of subsequent sensitization or disease; however, the presence of Lctbs at 6 months of age was associated with increased risk of subsequent cow's milk sensitization. Early probiotic supplementation with Lctbs acidophilus did not reduce the risk of $\mathrm{AD}$ in high-risk infants and was associated with increased allergen sensitization in infants receiving supplements. There were 3 major differences between Taylor's study and the others. The type of probiotic product (Lctbs acidophilus), the supplementation period (1 year) as well as the timing of the introduction of the probiotic were different. Taylor et al administered the probiotic supplement postnatally, while other studies administered probiotics before and after birth. Prenatal supplementation may prove to be crucial for the preventive benefit of probiotics in this disorder. The data from the Taylor et al's study point in the same direction regarding allergic sensitization, also suggesting that the use of probiotics for primary prevention must be exercised with caution [87].

Similarly, a randomized, double-blind, placebo-controlled prospective trial by Kopp et al of probiotics for primary prevention did show no clinical effects of LGG supplementation. 105 pregnant women from families with $\geq 1$ member (mother, father, or child) with an atopic 
disease were randomly assigned to receive either the probiotic LGG or pacebo. The supplementation period started 4 to 6 weeks before expected delivery, followed by a postnatal period of 6 months. The primary end point was the occurrence of $\mathrm{AD}$ at the age of 2 years. Secondary outcomes were severity of AD, recurrent episodes of wheezing bronchitis, and allergic sensitization at the age of 2 years. Notably, children with recurrent $(\geq 5)$ episodes of wheezing bronchitis were more frequent in the LGG group $(26 \%)$, as compared with the placebo group (9\%). As a result, supplementation with LGG during pregnancy and early infancy neither reduced the incidence of AD nor altered the severity of $\mathrm{AD}$ in affected children but was associated with an increased rate of recurrent episodes of wheezing bronchitis. No difference was observed between both groups in total Ig E concentrations or numbers of specific sensitization to inhalant allergens [88].

Furthermore; prenatal probiotic LGG treatment during pregnancy was not associated with reduced risk of eczema or IgE-associated eczema in a randomized controlled trial by Boyle RJ [51]. In a recent study, 250 pregnant women were recruited carrying infants at high risk of allergic disease to a randomized controlled trial of probiotic supplementation (LGG) from 36 weeks gestation until delivery. Gruber et al's study also did not show any effect for LGG in infants with AD regardless of their IgE sensitization status [89].

However, a study from the Netherlands by Brouwer et al and another study from Germany by Folster-Holst et al showed no effect of LGG in infants with AD regardless of their IgE sensitization status. In a study conducted by Brouwer et al, after 4-6 weeks of baseline and double-blind, placebo-controlled challenges for diagnosis of cow's milk allergy, infants less than 5 months old with AD received a hydrolysed whey-based formula as placebo (n:17), or supplemented with either Lctbs rhamnosus (n:17) or LGG (n:16) for 3 months. No statistically significant effects of probiotic supplementation on SCORAD, sensitization, inflammatory parameters or cytokine production between groups were found. No clinical or immunological effect of the probiotic bacteria used in infants with AD [47]. A similar prospective study by Fölster-Holst et al was performed to reassess the efficacy of orally administered LGG in infants with AD. In a randomized, double-blind, placebo-controlled study, 54 infants aged 1-55 months with moderate to severe AD were randomized to receive LGG or to placebo during an 8-week intervention phase. At the end of treatment there were no significant differences between the groups with respect to clinical symptoms (SCORAD, pruritus, and sleep loss), immunological parameters, or health-related quality of life of the parents [90]. Additionally; Soh et al in a clinical trial involving 253 infants with a family history of allergic disease utilized probiotic supplementation (Bfdbm longum + Lctbs rhamnosus) in the first 6 months of life in Asian infants at risk and evaluated the effects on eczema and atopic sensitization at the age of 1 year. Early life administration of a cow's milk formula supplemented with probiotics showed no effect on prevention of eczema or allergen sensitization in the first year of life in Asian infants at risk of allergic disease [91]. In conclusion; LGG was mostly used probiotic species in these studies. Firstly used by Kalliomaki et al [16] with a success however, other groups including Brouwer, Boyle, Kopp, Gruber, and Fölster -Holst et al $[47,51,87,88,90]$ could not demonstrate any benefit in AD. For instance: Kopp et al have shown that the probiotic LGG has no preventive effect on the development or the severity of $\mathrm{AD}$ at the age of 2 years in a German population of infants at high risk. Instead, there was a significantly higher risk of $\geq 5$ episodes with wheezing bronchitis during the first 2 years in the LGG group, as compared with placebo. There were several methodological differences between these studies: Kopp et al adapted the protocol 
of Kalliomäki et al and continued to supplement LGG for 3 months after birth to the breastfeeding mothers and the following 3 months only to the neonates. This modification was made to achieve a more consistent probiotic delivery. Second, Finnish mothers received supplementation during the last 4 weeks of pregnancy, whereas pregnant women in this population commenced with LGG or placebo for 4 to 6 weeks. They extended the prenatal supplementation period, because a 4-week period is thought to possibly be too short for suspected in utero effects of LGG supplementation. Also, population in this study by Kopp et al was being of higher risk compared with the Finnish population, which might account for the differing results. And more infants with older siblings were recruited compared with the Finnish study. Lastly, the Finnish and German populations are of different genetic background.

\section{Recent metaanalyses and reviews from literature}

A metaanalysis of the evidence from randomized controlled trials by Betsi et al on probiotics for the treatment or prevention of $\mathrm{AD}$ : the results of 13 relevant randomized (placebo)controlled trials were reviewed: 10 of which evaluated probiotics as treatment and 3 for prevention of AD. Four RCTs suggested that there was a statistically significant decrease in SCORAD after probiotic administration to infants or children with AD for 1 or 2 months compared with that after placebo. While in two RCTs SCORAD was significantly reduced after treatment with Lactobacilli only in children with IgE-associated AD. In three RCTs, the change in SCORAD was not statistically significant between probiotic- and placebo-treated children, although in one of these trials SCORAD was significantly lower after probiotic than with placebo treatment in food-sensitized children. As a result; probiotics, especially Lctbs rhamnosus GG, seem to be effective for the prevention of $\mathrm{AD}$ and they were also found to reduce the severity of $\mathrm{AD}$ in approximately half of the RCTs evaluated [53]. Likewise, Zhu et al did a metaanalysis of lactic acid bacteria as probiotics for the primary prevention of infantile eczema. The data from this metaanalysis suggested that lactic acid probiotics combined with other probiotics play a role in the prevention of infantile eczema. Conversely, another recent meta-analysis did not show a therapeutic difference among children receiving probiotics. This analysis excluded six of the ten studies published, making the validity of the report questionable [92].

In a review article; atopic disease and / or food hypersensitivity outcomes were assessed by Osborn et al in 6 studies enrolling 2080 infants, but outcomes for only 1549 infants were reported. Meta-analysis of five studies reporting the outcomes of 1477 infants found a significant reduction in infantile eczema. When the analysis was restricted to studies reporting atopic eczema (confirmed by skin prick test or specific $\operatorname{IgE}$ ), the findings were no longer significant. All studies reporting significant benefits used probiotic supplements containing Lctbs rhamnosus and enrolled infants at high risk of allergy [93]. Another recent meta-analysis suggested that probiotics may benefit children and infants with the disorder. The metaanalysis identified 10 randomized, controlled trials. A significant overall benefit was demonstrated after the use of probiotics, resulting in a reduction of the SCORAD scores compared to placebo. LGG appeared to be more effective than other probiotic preparations and children with more severe disease were more likely to benefit from the use of probiotics [94]. This remarkable meta-analysis was done to determine whether probiotics are efficacious in treating $\mathrm{AD}$ and to explore whether type of probiotic used, duration of therapy, patient age, severity of disease, and $\operatorname{IgE}$ sensitization are factors in determining 
efficacy. For this meta-analysis of randomized controlled trials describing the efficacy of probiotics in $\mathrm{AD}$, a comprehensive search was performed of databases through January 2008. Eleven studies were identified, and data from 10 studies ( $n: \geq 678$ ) were available to analyze. There was an overall statistically significant difference favoring probiotics compared with placebo in reducing the SCORAD index. Children with moderately severe disease were more likely to benefit. Duration of probiotic administration, age, and type of probiotic used did not affect outcome. Data from this meta-analysis suggest a modest role for probiotics in pediatric AD and the effect is seen in moderately severe rather than mild disease [94]. Lee et al meta-analyzed 10 double-blind randomized controlled clinical trials. And they found out that current evidence was more convincing for probiotics' efficacy in prevention than treatment of pediatric AD [95].

However, in a Cochrane Review by Boyle et al concluded that the evidence suggests that probiotics are not an effective treatment for eczema, and probiotic treatment carries a small risk of adverse events [96]. Another review of 13 studies of probiotics for treating established eczema by Williams at al did not show convincing evidence of a clinically worthwhile benefit [97].

Taken together, most of these metaanalytic studies show a mild-moderate benefit over placebo for the treatment and/or preventionof AD. However, several of the studies still show no benefit. Some probiotics appeared to be more effective than other probiotic preparations and in children with more severe disease. It seems that duration of probiotic administration, age, and type of probiotic used did not affect outcome. Although there was a reduction in clinical eczema score in infants, this effect was not consistent between studies and caution is advised in view of methodological concerns regarding included studies.

\section{Affecting factors coexisting in various studies and why inconsistent results in some studies?}

Most of the studies have been conducted in small numbers of patients and results have varied considerably, even with the same strain of probiotics. When compared to the hallmark Finnish Kalliomaki study, there were also a number of other key differences between these studies that could contribute to the disparity in clinical findings. Firstly (biological difference of probiotic strains), different probiotic species were used in various studies. Lctbs rhamnosus GG is the strain that has been most studied. Probiotic doses have also varied considerably between the studies. Although there are noted biological differences between strains, various strains have been observed to have different immunologic effects both in vivo and in vitro [35]. Thus, the effects of preparations differ markedly, and the concept itself might be misleading in these studies and could be changed: continuous change in the supplemented strain could lead to continued immunologic stimulus and sustained and stronger effects. As a result, on the basis of these studies, immunologic effects expressed as chronic low-grade inflammation were more pronounced with LGG alone rather than with the mixture of 4 strains used in some prevention studies [57]. This might explain the more sustained preventive effect observed earlier. The results of various studies also demonstrate that findings from any probiotic bacteria cannot be extrapolated to other probiotic bacteria [20]. Secondly (use of probiotics in prenatal/intrauterine or postnatal or weaning period), Finnish mothers commenced supplementation during pregnancy, whereas some supplementation began in the first days of life. Prenatal/intrauterine use of probiotics would imply a direct immune effect in utero rather than any effect on postnatal colonization. However, it seems unlikely that supplementation for 
only a few weeks in the antenatal period alone would account for such significant differences in study outcomes, although this remains a possibility. Thirdly (intervention methods), in most studies all babies received the supplement directly, regardless of feeding method, whereas in the Finnish and other studies, the mother took the probiotics if babies were breastfed. Therefore, the Finnish probiotic group and others included breast-fed infants who did not receive probiotics directly in addition to the bottle-fed infants who received probiotics for 6 months. Fourthly (postnatal assessment time), some researchers assessed clinical outcomes at 12 months of age, whereas the effects on AD in the Finnish or other studies were reported at 2, 4 and subsequently at 7 years of age. AD typically begins in the first year of life, and it is possible that more children could become affected in their second year of life. And in young infants, the immune system is still developing. There is still a possibility to direct it toward tolerance. In older children, the allergic phenotype is already established, and here one may only be able to relieve the symptoms. Fifthly (atopy risk and host factors of targeted group), some studies were performed in high-risk population all had maternal allergic disease confirmed by SPT, whereas the Finnish and other population included children with maternal, paternal, or sibling allergy. This may lead to some population being of slightly higher risk, compared with the Finnish and other population at the same age. Explanations for varied study results include host factors such as genetic susceptibility, environmental factors such as geographic region and diet [98]. Genotyping of study patients in relation to different genes predisposing to allergic diseases may help to find patients that might especially benefit from probiotic intervention. For example, 2 independent mutations in the gene encoding the epidermal protein filaggrin have been shown to be strong predisposing factors for childhood eczema [99]. Of note, these same mutations have recently been demonstrated to be associated not only with eczema-associated asthma susceptibility but also with asthma severity independent of eczema status. More generally, any means to better stratify or select defined subpopulations of subjects (e.g. patients with food allergy as a separate group) would help in clarifying the potency and limits of probiotic interventions against atopic diseases. Sixthly (other methodological set-up), there may be still due to differences in the clinical and methodological set-up (additional treatments such as topical treatment or feeding hydrolyzed infant formulae and importantly, different probiotic preparations or formulations or combinations). Other differences include age (6-18 months) of the studied children and an intervention period (16 weeks) of time. Seventhly (nomenclature of the disease), to date, randomized clinical trials of probiotics in allergic diseases have mostly focused on children with eczema and atopic eczema. The definitions of the disease have recently been revised by an international expert group [17-19]. In many of the studies published before the revision of the nomenclature, different definitions have been used, making direct comparisons between the studies difficult. The severity of $\mathrm{AD}$ at the start of an intervention may influence the outcome as well, as you imagine.

\section{Safety}

Probiotics available as food ingredients or dietary supplements that contain microorganisms have been used extensively in food processing for years, with a long history of safety and no adverse effects on metabolism. However, when considering the safety of probiotics, potential adverse effects include systemic infections, altered metabolism, and gene transfer [100]. A recent report has identified Lctbs septicemia in 2 children with short bowel syndrome who were receiving LGG supplementation for control of bacterial overgrowth 
[101]. Land et al recently reported LGG probiotic sepsis occurring in immunocompromised infants and children [102]. A medically fragile infant 6 weeks of age became septic with a strain of LGG that was being provided as a supplement. Molecular DNA fingerprinting confirmed that the LGG probiotic supplement was the bacterial isolate from the infant. Neonatal sepsis and meningitis that were apparently associated with the administration of a probiotic supplement were also reported [103,104]. Children with abnormal immune function, premature infants, and those with indwelling central lines should use these products with caution, because many species such as Lactobacilli, streptococci, and enterococci are potential opportunistic pathogens. Owing to the theoretical risk of immunomodulation, especially in immunocompromised hosts or those with autoimmune disorders, few reports of probiotic-related disease have been reported [105].

Bifidobacteria have also been consumed in infant formulas for $\geq 15$ years worldwide and have not been associated with any pathologic or adverse event. In particular, studies have documented safety and adequate growth with Bfdbm lactis in infants from birth and in vulnerable populations, including preterm infants, malnourished infants, and infants born to mothers with HIV disease. From the safety point of view, according to current available information, Bifidobacteria, particularly Bfdbm lactis, has a uniquely strong safety profile, making it a good probiotic candidate for newborns and young infants [106]. Lactobacilli, particularly Lctbs rhamnosus (LGG), also seem generally safe and may be a probiotic appropriate for older infants and children [107]. Until adequate data are available for each specific probiotic bacterium, use of probiotics in general cannot be recommended in immunocompromised populations. However, as safety is better documented for specific bacteria, we may be able to use them in certain populations (such as premature infants) that may stand to benefit the most from probiotic use.

Another consideration is that cow's milk protein allergy is one of the common food allergies in infants. Culture conditions used in growing several probiotic products may contain cow's milk protein. There have been reports of severe adverse reactions when pediatric patients with cow's milk protein allergy ingested probiotics. Therefore, caution should be used in prescribing such probiotic products in sensitized children to avoid significant reactions. There is also a study worth mentioning by Taylor et al using Lctbs acidophilus daily for the first 6 months of life in newborns of women with allergy. The presence of Lctbs in the body at 6 months of age was associated with increased risk of subsequent cow's milk sensitization as well [87]. Nevertheless other studies have examined the effect of probiotic consumption on sensitization to several allergens (e.g. peanut, hen's egg, soy, wheat, milk, cat, dog), as determined by specific IgE production or skin prick test. The authors could not find a difference before and after the treatment. Interesting another trial by Kopp et al demonstrated that supplementation with LGG during pregnancy and early infancy in affected children it might be associated with an increased rate of recurrent episodes of wheezing bronchitis [88]. However, a recent study was done by Kukkonen et al evaluating airway inflammation in probiotic-treated children at 5 years in 1018 children. Early intervention with probiotics and prebiotics did not affect airway inflammation later in childhood [108].

Furthermore, similarly certain probiotics are known to stimulate Th1 immunity, which has been suggested as one of the mechanisms by which they can suppress Th2-mediated allergic diseases. However, this presumed excessive immunostimulation might aggravate or induce Th1-mediated immune responses and diseases such as type 1 diabetes, multiple sclerosis; and it might cause an additional safety issue [105]. Consequence of over-activation of the 
immune system by probiotics in hosts with immune dysfunctions, such as individuals genetically predisposed to autoimmunity, has raised some concerns too. With respect to the association between bacterial antigens and autoimmune responses and the adjuvant activity of lactic acid bacteria strains, the involvement of lactic acid bacteria in the pathogenesis of some models of autoimmunity in experimental animals and possibly in humans has been suggested [109]. Thus, from a safety point of view, the potential of probiotic bacteria (especially the immunostimulatory strains), to induce destructive inflammation or autoimmunity needs to be investigated. For instance, it has been experimentally demonstrated that Lctbs casei cell wall components (given intraperitoneally) are able to induce cardioangitis (an autoimmunity-associated heart disease) in mice [110].

\section{Conclusion}

As mentioned above, there is a large amount of conflicting data on the preventive/therapeutic effects of probiotics in AD. Results from metaanalyses and systematic reviews that combine results of studies from different types of probiotics to examine the effects in any disease should be interpreted with caution. One may quickly recognize the degree of heterogeneity among the different probiotic studies. As mentioned, very few studies were similar in design. Several different probiotic strains with different dosing regimens were used, and many studies showed similarity in efficacy to placebo shortly after probiotic therapy was discontinued. Some probiotic studies suggest short-term statistically significant improvement in SCORAD scores and no sustained benefit from continued ingestion. Therefore, subgroup analysis became critical in understanding the outcomes of the studies. Not all children receiving the probiotic agent benefited, but subsets of these patients, mainly those with moderate disease activity and IgE-associated disease (atopic eczema), seemed to have benefited the most. There are also difficulties of recognizing etiology and pathogenesis of $\mathrm{AD}$ in which have many mechanisms involved. Similarly, with various strains, especially e.g. in Kopp and Taylor et al's study, development and/or stimulation of Th2-mediated immune responses have been described $[87,88]$. Additionally, if probiotics are used in patients with ADs for any reason -therapy or prevention- cautionary approach ought to be taken. Thus, probiotics cannot be recommended generally for primary prevention of ADs. Any probiotics should not be used especially in immune-compromised children; even they have at risk for ADs. Finally, there is insufficient but fairly promising evidence to recommend the addition of probiotics to foods for prevention and treatment of AD [111].

\section{Five-year view and future expectations}

Involvement of commensal enteric microflora and its components with strong immunoactivating properties in etiopathogenetic mechanism of multifactorial diseases, including atopic diseases has been recently suggested. Regulation of intestinal microflora composition (e.g. by probiotics) offers the possibility to influence the development of mucosal and systemic immunity as well as it can play a role also in prevention and treatment of AD. Progress has been made by the identification of receptors and pathways through which gut microbes influence development of the immune system. Such mechanistic data have moved a field that was once regarded as being on the scientific fringe to the mainstream, and support increased funding to advance this promising area of research in the hope that it might deliver the long awaited answer of how to safely prevent AD. 
Better understanding of the effects of different probiotic strains and a deeper insight into the mechanisms of the heterogeneous manifestations of $\mathrm{AD}$ are needed for the validation of specific strains carrying anti-allergic potential. Therefore, research activities are currently focusing on identification of specific probiotic strains with immunomodulatory potential and on how dietary content interacts with the most efficacious probiotic strains. Moreover, the selection of the most beneficial probiotic strain, the dose, and the timing of supplementation still need to be determined. Further studies should also clarify if any susceptible groups of $\mathrm{AD}$ exist and how these groups benefit from supplementation with certain probiotic strains.

Some studies in the management of $\mathrm{AD}$ suggest that therapeutic benefit requires a combination of probiotic species (as with VSL\#3 or Lacto-mix) or that the component(s) responsible for the anti-inflammatory effect in combination preparations have specific properties that monotherapy probiotics do not [112]. This concept also supports the use of prebiotics that increase concentrations of several commensal immunoregulatory bacteria. Prebiotic use was shown to be associated with a reduction in the faecal concentration of Bacteroides fragilis, but had no effect on Lactobacilli or Bifidobacteria. Genetically modified probiotics will be tested for their ability to attenuate AD thru secreting regulatory cytokines in experimental models as well [113]. In near future, the researchers will look for more appropriate combinations of probiotic species or modified probiotics with/without prebiotic and test them in human/experimental AD models.

Additionally, side effects are very low and they might not be nonexistent, as shown in a set of patients with different diseases. However, probiotics should not be considered as totally harmless, particularly in the immunodeficient host, and more safety studies are needed. As imagined, probiotics may have unpredictable behaviour like all microorganisms, such as unanticipated gene expression in nonnative host environment, or acquired mutations occurring spontaneously via bacterial DNA-transfer mechanisms [114]. And certain probiotics are known to stimulate Th1 immunity, which has been suggested as one of the mechanisms by which they can suppress Th2-mediated allergic diseases [110].

\section{Key issues}

- Since conclusions on probiotics are limited to specific strains and models, they should not be generalized [20,35].

- Probiotics should not be considered as completely harmless, particularly in the immunodeficient host, and more safety studies are needed [100-110, 115,116].

- Physiological use (normal route, normal dose, normal growth phase, specific strain or substrain/species) is studied in all cases, so as not to overwhelm (high dose) or circumvent natural immune processing [100-110].

- Do probiotics really induce/exacerbate Th1 and / or Th2- mediated diseases? Such as being reported an increased rate of recurrent wheezing episodes, an augmented rate of atopic disorders, increased sensitization to allergens as well as autoimmune disorders. Lactobacilli and Bifidobacteria have specific dose- and duration- dependent immunomodulatory effects on the proliferation of B-/T-lymphocytes [108-110].

- The researchers ought to look for more appropriate and safe combinations of probiotic species (as with VSL\#3 or Lacto-mix) or modified probiotics with/without prebiotic and test them in human/experimental AD models [112].

- Research activities are currently focusing on identification of specific probiotic strains with immunomodulatory potential and on how dietary content interacts with the most 
efficacious probiotic strains. Further studies should be made for the identification of receptors and pathways through which gut microbes influence development of the immune system $[117,118]$.

\section{References}

[1] Prescott SL, Macaubas C, Holt BJ, Smallacombe TB, Loh R, Sly PD, Holt PG. Transplacental priming of the human immune system to environmental allergens: universal skewing of initial $\mathrm{T}$ cell responses toward the Th2 cytokine profile. J Immunol 1998; 160: 4730-7.

[2] Cabana MD, McKean M, Wong AR, Chao C, Caughey AB. Examining the hygiene hypothesis: the Trial of infant probiotic supplementation. Paediatr Perinat Epidemiol 2007; 21 Suppl 3: 23-8.

[3] Björkstén B, Sepp E, Julge K, Voor T, Mikelsaar M. Allergy development and the intestinal microflora during the first year of life. J Allergy Clin Immunol 2001; 108: 516-20.

[4] Renz-Polster H, David MR, Buist AS, Vollmer WM, O'Connor EA, Frazier EA, Wall MA. Caesarean section delivery and the risk of allergic disorders in childhood. Clin Exp Allergy 2005; 35: 1466-72.

[5] Newburg DS. Oligosaccharides in human milk and bacterial colonization. J Pediatr Gastroenterol Nutr 2000; 30(suppl 2): S8-17.

[6] Matsuki T, Watanabe K, Tanaka R, Fukuda M, Oyaizu H. Distribution of bifidobacterial species in human intestinal microflora examined with 16S rRNA-gene-targeted species-specific primers. Appl Environ Microbiol 1999; 65: 4506-12.

[7] Harmsen HJ, Wildeboer-Veloo AC, Raangs GC, Wagendorp AA, Klijn N, Bindels JG, Welling GW. Analysis of intestinal flora development in breast-fed and formula-fed infants by using molecular identification and detection methods. J Pediatr Gastroenterol Nutr 2000; 30: 61-7.

[8] Yoshioka H, Iseki K, Fujita K. Development and differences of intestinal flora in the neonatal period in breast-fed and bottle-fed infants. Pediatrics 1983; 72: 317-21.

[9] Kalliomaki M, Kirjavainen P, Eerola E, Kero P, Salminen S, Isolauri E. Distinct patterns of neonatal gut microflora in infants in whom atopy was and was not developing. J Allergy Clin Immunol 2001; 107: 129-34.

[10] Gareau MG, Sherman PM, Walker WA. Probiotics and the gut microbiota in intestinal health and disease.Nat Rev Gastroenterol Hepatol. 2010; 7(9): 503-14.

[11] Metchnikoff E. The Prolongation of Life: Optimistic Studies. London: G. P. Putnam \& Sons; 1907.

[12] Food and Agriculture Organization, World Health Organization. Report of Joint FAO/WHO expert consultation on evaluation of health and nutritional properties of probiotics in food including powder milk with live lactic acid bacteria. FAO/WHO Report No. 10-1-2001.

[13] Özdemir Ö. Various effects of different probiotic strains in allergic disorders: an update from laboratory and clinical data. Clin Exp Immunol. 2010; 160(3), 295-304.

[14] Özdemir Ö. Any Benefits of Probiotics in Allergic Disorders? Allergy Asthma Proc 2010; 31, 103-11.

[15] Majamaa H, Isolauri E. Probiotics. A novel approach in the management of food allergy. J Allergy Clin Immunol 1997; 99: 179-85. 
[16] Kalliomäki M, Salminen S, Poussa T, Isolauri E. Probiotics during the first 7 years of life: a cumulative risk reduction of eczema in a randomized, placebo- controlled trial. J Allergy Clin Immunol 2007, 119(4):1019-21.

[17] Darsow U, Wollenberg A, Simon D, Taïeb A, Werfel T, Oranje A, et al. ETFAD/EADV eczema task force 2009 position paper on diagnosis and treatment of atopic dermatitis. J Eur Acad Dermatol Venereol. 2010; 24(3): 317-28. doi: 10.1111/j.14683083.2009.03415.x

[18] Colin R Simpson, John Newton, Julia Hippisley-Cox, Aziz Sheikh. Trends in the epidemiology and prescribing of medication for eczema in England. J R Soc Med 2009: 102: 108-117. doi: 10.1258/jrsm.2009.080211.

[19] Bongaerts GP, Severijnen RS. Preventive and curative effects of probiotics in atopic patients. Med Hypotheses. 2005;64(6):1089-92.

[20] Walker WA. Mechanisms of action of probiotics. Clin Infect Dis 2008; 46 Suppl 2:S87-91; discussion S144-51.

[21] Björkstén B, Naaber P, Sepp E, Mikelsaar M. The intestinal microflora in allergic Estonian and Swedish 2-year-old children. Clin Exp Allergy. 1999; 29(3): 342-6.

[22] Watanabe S, Narisawa Y, Arase S, Okamatsu H, Ikenaga T, Tajiri Y, Kumemura M. Differences in fecal microflora between patients with atopic dermatitis and healthy control subjects. J Allergy Clin Immunol 2005, 111(3): 587-91.

[23] Kirjavainen PV, Arvola T, Salminen SJ, Isolauri E. Aberrant composition of gut microbiota of allergic infants: a target of bifidobacterial therapy at weaning? Gut 2002; 51-55.

[24] Sepp E, Julge K, Mikelsaar M, Björkstén B. Intestinal microbiota and immunoglobulin E responses in 5-year-old Estonian children. Clin Exp Allergy 2005, 35(9): 1141-6.

[25] Adlerberth I, Strachan DP, Matricardi PM, Ahrné S, Orfei L, Aberg N, et al. Gut microbiota and development of atopic eczema in 3 European birth cohorts. J Allergy Clin Immunol 2007, 120(2): 343-50.

[26] Penders J, Stobberingh EE, Thijs C, Adams H, Vink C, van Ree R, van den Brandt PA et al. Molecular finger printing of the intestinal microbiota of infants in whom atopic eczema was or was not developing. Clin Exp Allergy 2006, 36(12): 1602-8.

[27] Sudo N, Sawamura S, Tanaka K, Aiba Y, Kubo C, Koga Y. The requirement of intestinal bacterial flora for the development of an IgE production system fully susceptible to oral tolerance induction. J Immunol 1997; 159: 1739-45.

[28] Viljanen M, Kuitunen M, Haahtela T, Juntunen-Backman K, Korpela R, Savilahti E. Probiotic effects on faecal inflammatory markers and on faecal IgA in food allergic atopic eczema/dermatitis syndrome infants. Pediatr Allergy Immunol 2005; 16: 65-71.

[29] Isolauri E. Studies on Lactobacillus GG in food hypersensitivity disorders. Nutr Today Suppl 1996; 31: 285-315.

[30] Cebra JJ. Influences of microbiota on intestinal immune system development. Am J Clin Nutr 1999; 69: 1046S-1051S.

[31] Malin MV, Korhonen H, Syvaoja EL, et al. Dietary therapy with lactobacillus GG, bovine colostrum or bovine immune colostrum in patients with juvenile chronic arthritis: evaluation of effect on gut defense mechanisms. Inflammopharmacology 1997; 5: 219-36. 
[32] Pessi T, Isolauri E, Sutas Y, Kankaanranta H, Moilanen E, Hurme M. Suppression of T cell activation by Lactobacillus rhamnosus GG-degraded bovine casein. Immunopharmacology 2001; 1: 211-8.

[33] Kaila M, Isolauri E, Soppi E, Virtanen E, Laine S, Arvilommi H. Enhancement of the circulating antibody secreting cell response in human diarrhea by a human Lactobacillus strain. Pediatr Res 1992; 32: 141-4.

[34] Ruemmele FM, Bier D, Marteau P, Rechkemmer G, Bourdet-Sicard R, Walker WA, Goulet O. Clinical evidence for immunomodulatory effects of probiotic bacteria. J Pediatr Gastroenterol Nutr 2009; 48: 126-41.

[35] Christensen HR, Frokiaer H, Pestka JJ. Lactobacilli differentially modulate expression of cytokines and maturation surface markers in murine dendritic cells. J Immunol 2002; 168: 171-8.

[36] Salminen SJ, Gueimonde M, Isolauri E. Probiotics that modify disease risk. J Nutr 2005; 135: 1294-8.

[37] Niers LE, Timmerman HM, Rijkers GT et al. Identification of strong interleukin-10 inducing lactic acid bacteria which downregulate $\mathrm{T}$ helper type 2 cytokines. Clin Exp Allergy 2005; 35: 1481-9.

[38] Maassen CB, van Holten-Neelen C, Balk F, den Bak-Glashouwer MJ, Leer RJ, Laman JD, Boersma WJ, Claassen E. Strain-dependent induction of cytokine profiles in the gut by orally administered Lactobacillus strains. Vaccine 2000; 18: 2613-23.

[39] Kruisselbrink A, Heijne Den Bak-Glashouwer MJ, Havenith CE, Thole JE, Janssen R. Recombinant Lactobacillus plantarum inhibits house dust mite-specific T-cell responses. Clin Exp Immunol 2001; 126: 2-8.

[40] West CE, Hammarström ML, Hernell O. Probiotics during weaning reduce the incidence of eczema. Pediatr Allergy Immunol. 2009;20(5):430-7.

[41] Sistek D, Kelly R, Wickens K, Stanley T, Fitzharris P, Crane J. Is the effect of probiotics on atopic dermatitis confined to food sensitized children? Clin Exp Allergy 2006; 36: 629-33.

[42] Kim JY, Choi YO, Ji GE. Effect of oral probiotics (Bifidobacterium lactis AD011 and Lactobacillus acidophilus AD031) administration on ovalbumin-induced food allergy mouse model. J Microbiol Biotechnol 2008; 18: 1393-1400.

[43] Takahashi N, Kitazawa H, Iwabuchi N, Xiao JZ, Miyaji K, Iwatsuki K, Saito T. Immunostimulatory oligodeoxynucleotide from Bifidobacterium longum suppresses Th2 immune responses in a murine model. Clin Exp Immunol 2006; 145:130-8.

[44] Shida K, Makino K, Morishita A. Lactobacillus casei inhibits antigen induced IgE secretion through regulation of cytokine production in murine splenocyte cultures. Int Arch Allergy Immunol 1998;115:278-87.

[45] Thomas DJ, Husmann RJ, Villamar M, Winship TR, Buck RH, Zuckermann FA. Lactobacillus rhamnosus HN001 attenuates allergy development in a pig model. PLoS One. 2011; 6(2): e16577.

[46] Rosenfeldt V, Benfeldt E, Nielsen SD, Michaelsen KF, Jeppesen DL, Valerius NH, Paerregaard A. Effect of probiotic Lactobacillus strains in children with atopic dermatitis. J Allergy Clin Immunol 2003; 111: 389-95. 
[47] Brouwer ML, Wolt-Plompen SA, Dubois AE, van der Heide S, Jansen DF, Hoijer MA, Kauffman HF, Duiverman EJ. No effects of probiotics on atopic dermatitis in infancy: a randomized placebo-controlled trial. Clin Exp Allergy. 2006; 36(7): 899-906.

[48] Pohjavuori E, Viljanen M, Korpela R, Kuitunen M, Tiittanen M, Vaarala O, Savilahti E.Lactobacillus GG effect in increasing IFN-gamma production in infants with cow's milk allergy. J Allergy Clin Immunol. 2004; 114(1): 131-6.

[49] Prescott SL, Dunstan JA, Hale J, Breckler L, Lehmann H, Weston S, Richmond P. Clinical effects of probiotics are associated with increased interferon-gamma responses in very young children with atopic dermatitis. Clin Exp Allergy. 2005; 35(12): 1557-64.

[50] Isolauri E, Arvola T, Sütas Y, Moilanen E, Salminen S. Probiotics in the management of atopic eczema. Clin Exp Allergy. 2000; 30(11):1604-10.

[51] Boyle RJ, Ismail IH, Kivivuori S, Licciardi PV, Robins-Browne RM, Mah LJ, et al. Lactobacillus GG treatment during pregnancy for the prevention of eczema: a randomized controlled trial. Allergy. 2011;66(4):509-16. doi: 10.1111/j.13989995.2010.02507.x.

[52] Böttcher MF, Abrahamsson TR, Fredriksson M, Jakobsson T, Björkstén B.Low breast milk TGF-beta2 is induced by Lactobacillus reuteri supplementation and associates with reduced risk of sensitization during infancy. Pediatr Allergy Immunol. 2008;19(6):497-504.

[53] Betsi GI, Papadavid E, Falagas ME. Probiotics for the treatment or prevention of atopic dermatitis: a review of the evidence from randomized controlled trials. Am J Clin Dermatol 2008; 9: 93-103.

[54] Chiba Y, Shida K, Nagata S, Wada M, Bian L, Wang C, et al. Well-controlled proinflammatory cytokine responses of Peyer's patch cells to probiotic Lactobacillus casei. Immunology. 2010; 130(3):352-62.

[55] Lavasani S, Dzhambazov B, Nouri M, Fåk F, Buske S, Molin G, Thorlacius H, Alenfall J, Jeppsson B, Weström B. A novel probiotic mixture exerts a therapeutic effect on experimental autoimmune encephalomyelitis mediated by IL-10 producing regulatory T cells. PLoS One. 2010; 5(2): e9009.

[56] Woo SI, Kim JY, Lee YJ, Kim NS, Hahn YS. Effect of Lactobacillus sakei supplementation in children with atopic eczema-dermatitis syndrome.Ann Allergy Asthma Immunol. 2010; 104(4): 343-8.

[57] Marschan E, Kuitunen M, Kukkonen K, Poussa T, Sarnesto A, Haahtela T, Korpela R, Savilahti E, Vaarala O. Probiotics in infancy induce protective immune profiles that are characteristic for chronic low-grade inflammation. Clin Exp Allergy. 2008; 38(4): 611-8.

[58] Niers LE, Hoekstra MO, Timmerman HM, van Uden NO, de Graaf PM, Smits HH, Kimpen JL, Rijkers GT. Selection of probiotic bacteria for prevention of allergic diseases: immunomodulation of neonatal dendritic cells. Clin Exp Immunol 2007; 149: 344-52.

[59] Hart AL, Lammers K, Brigidi P et al. Modulation of human dendritic cell phenotype and function by probiotic bacteria. Gut 2004; 53: 1602-9.

[60] Braat H, van den Brande J, van Tol E, Hommes D, Peppelenbosch M, van Deventer S. Lactobacillus rhamnosus induces peripheral hyporesponsiveness in stimulated 
CD4+ T cells via modulation of dendritic cell function. Am J Clin Nutr 2004; 80: 1618-25.

[61] Smits HH, Engering A, van der Kleij D et al. Selective probiotic bacteria induce IL-10producing regulatory $\mathrm{T}$ cells in vitro by modulating dendritic cell function through dendritic cell-specific intercellular adhesion molecule 3-grabbing nonintegrin. J Allergy Clin Immunol 2005; 115: 1260-7.

[62] Kim JY, Choi YO, Ji GE. Effect of oral probiotics (Bifidobacterium lactis AD011 and Lactobacillus acidophilus AD031) administration on ovalbumin-induced food allergy mouse model.J Microbiol Biotechnol. 2008;18(8):1393-400.

[63] Feleszko W, Jaworska J, Rha RD et al. Probiotic-induced suppression of allergic sensitization and airway inflammation is associated with an increase of $\mathrm{T}$ regulatory-dependent mechanisms in a murine model of asthma. Clin Exp Allergy 2007; 37: 498-505.

[64] Fujimura T, Okuyama R, Ito Y, Aiba S. Profiles of Foxp3+ regulatory T cells in eczematous dermatitis, psoriasis vulgaris and mycosis fungoides. Br J Dermatol. 2008; 158(6): 1256-63.

[65] Kwon HK, Lee CG, So JS, Chae CS, Hwang JS, Sahoo A, et al. Generation of regulatory dendritic cells and CD4+Foxp3+ T cells by probiotics administration suppresses immune disorders. Proc Natl Acad Sci USA 2010; 107(5): 2159-64.

[66] Hacini-Rachinel F, Gheit H, Le Luduec JB, Dif F, Nancey S, Kaiserlian D. Oral probiotic control skin inflammation by acting on both effector and regulatory T cells. PLoS One. 2009; 4(3): e4903.

[67] Taylor AL, Hale J, Hales BJ, Dunstan JA, Thomas WR, Prescott SL. FOXP3 mRNA expression at 6 months of age is higher in infants who develop atopic dermatitis, but is not affected by giving probiotics from birth. Pediatr Allergy Immunol 2007, 18(1): 10-9.

[68] Gerasimov SV, Vasjuta VV, Myhovych OO, Bondarchuk LI. Probiotic supplement reduces atopic dermatitis in preschool children: a randomized, double-blind, placebo-controlled, clinical trial. Am J Clin Dermatol. 2010; 11(5): 351-61. doi: 10.2165/11531420-000000000-00000.

[69] Roessler A, Friedrich U, Vogelsang H, Bauer A, Kaatz M, Hipler UC, Schmidt I, Jahreis G. The immune system in healthy adults and patients with atopic dermatitis seems to be affected differently by a probiotic intervention. Clin Exp Allergy. 2008; 38(1): 93-102.

[70] Hoarau C, Lagaraine C, Martin L, Velge-Roussel F, Lebranchu Y. Supernatant of Bifidobacterium breve induces dendritic cell maturation, activation, and survival through a Toll-like receptor 2 pathway. J Allergy Clin Immunol 2006; 117: 696-702.

[71] Forsythe P, Inman MD, Bienenstock J. Oral treatment with live Lactobacillus reuteri inhibits the allergic airway response in mice. Am J Respir Crit Care Med. 2007;175(6):561-9.

[72] Viljanen M, Savilahti E, Haahtela T, Juntunen-Backman K, Korpela R, Poussa T, Tuure T, Kuitunen M. Probiotics in the treatment of atopic eczema/dermatitis syndrome in infants: a double-blind placebo-controlled trial. Allergy. 2005; 60(4): 494-500.

[73] Kukkonen K, Savilahti E, Haahtela $\mathrm{T}$, et al. Probiotics and prebiotic galactooligosaccharides in the prevention of allergic diseases: a randomized, doubleblind, placebo-controlled trial. J Allergy Clin Immunol. 2007; 119(1): 192-8. 
[74] Kuitunen M, Kukkonen K, Juntunen-Backman K, Korpela R, Poussa T, Tuure T, Haahtela T, Savilahti E. Probiotics prevent IgE-associated allergy until age 5 years in cesarean-delivered children but not in the total cohort. J Allergy Clin Immunol 2009; 123: 335-41.

[75] Abrahamsson TR, Jakobsson T, Bottcher MF, et al. Probiotics in prevention of IgEassociated eczema: a double-blind, randomized, placebo-controlled trial. J Allergy Clin Immunol. 2007; 119(5): 1174-1180.

[76] Isolauri E, Rautava S, Kalliomäki M, Kirjavainen P, Salminen S. Role of probiotics in food hypersensitivity. Curr Opin Allergy Clin Immunol 2002; 2: 263-71.

[77] Kirjavainen PV, Salminen SJ, Isolauri E. Probiotic bacteria in the management of atopic disease: underscoring the importance of viability. J Pediatr Gastroenterol Nutr. 2003; 36(2): 223-7.

[78] Weston S, Halbert A, Richmond P, Prescott SL. Effects of probiotics on atopic dermatitis. A randomised controlled trial. Arch Dis Child 2005, 90(9): 892-7.

[79] Hoang BX, Shaw G, Pham P, Levine SA. Lactobacillus rhamnosus cell lysate in the management of resistant childhood atopic eczema. Inflamm Allergy Drug Targets. 2010; 9(3): 192-6.

[80] Hattori K, Yamamoto A, Sasai M, Taniuchi S, Kojima T, KobayashiY, et al. Effects of administration of bifidobacteria on fecal microflora and clinical symptoms in infants with atopic dermatitis. Arerugi 2003; 52: 20-30.

[81] Wickens K, Black PN, Stanley TV, et al. A differential effect of 2 probiotics in the prevention of eczema and atopy: a double-blind, randomized, placebo-controlled trial. J Allergy Clin Immunol 2008; 122: 788-94.

[82] Niers L, Martín R, Rijkers G, Sengers F, Timmerman H, van Uden N, et al. The effects of selected probiotic strains on the development of eczema (the PandA study). Allergy. 2009; 64(9): 1349-58.

[83] Kim JY, Kwon JH, Ahn SH, Lee SI, Han YS, Choi YO, et al. Effect of probiotic mix (Bifidobacterium bifidum, Bifidobacterium lactis, Lactobacillus acidophilus) in the primary prevention of eczema: a double-blind, randomized, placebo-controlled trial. Pediatr Allergy Immunol. 2010; 21(2 Pt 2): e386-93.

[84] Dotterud CK, Storrø O, Johnsen R, Oien T. Probiotics in pregnant women to prevent allergic disease: a randomized, double-blind trial. Br J Dermatol. 2010; 163(3): 61623. doi: 10.1111/j.1365-2133.2010.09889.x.

[85] Lodinova-Zadnikova R, Cukrowska B, Tlaskalova-Hogenova H. Oral administration of probiotic Escherichia coli after birth reduces frequency of allergies and repeated infections later in life (after 10 and 20 years). Int Arch Allergy Immunol 2003, 131(3): 209-11.

[86] Huurre A, Laitinen K, Rautava S, Korkeamäki M, Isolauri E. Impact of maternal atopy and probiotic supplementation during pregnancy on infant sensitization: a doubleblind placebo-controlled study. Clin Exp Allergy. 2008; 38(8):1342-8.

[87] Taylor A, Dunstan J, Prescott S. Probiotic supplementation for the first 6 months of life fails to reduce the risk of atopic dermatitis and increases the risk of allergen sensitization in high-risk children: a randomized controlled trial. J Allergy Clin Immunol 2007; 119:184-91. 
[88] Kopp MV, Isabell Hennemuth, Andrea Heinzmann, Radvan Urbanek. Randomized, double-blind, placebo-controlled trial of probiotics for primary prevention: No clinical effects of Lactobacillus GG supplementation. Pediatrics 2008; 121: e850-6.

[89] Grüber C, Wendt M, Sulser C, Lau S, Kulig M, Wahn U, Werfel T, Niggemann B. Randomized, placebo-controlled trial of Lactobacillus rhamnosus GG as treatment of atopic dermatitis in infancy. Allergy 2007; 62(11): 1270-6.

[90] Fölster-Holst R, Müller F, Schnopp N, Abeck D, Kreiselmaier I, Lenz T, von Rüden U, et al. Prospective, randomized controlled trial on Lactobacillus rhamnosus in infants with moderate to severe atopic dermatitis. Br J Dermatol 2006, 155(6): 1256-61.

[91] Soh SE, Aw M, Gerez I, et al. Probiotic supplementation in the first 6 months of life in at risk Asian infants--effects on eczema and atopic sensitization at the age of 1 year. Clin Exp Allergy 2009; 39: 571-8.

[92] Zhu DL, Yang WX, Yang HM. [Meta analysis of lactic acid bacteria as probiotics for the primary prevention of infantile eczema]. Zhongguo Dang Dai Er Ke Za Zhi. 2010; 12(9): 734-9.

[93] Osborn DA, Sinn JK. Probiotics in infants for prevention of allergic disease and food hypersensitivity. Cochrane Database Syst Rev 2007; 4:CD006475.

[94] Michail S, Onady G, Stolfi A, Johnson T. Efficacy of probiotics in treatment of pediatric atopic dermatitis a meta-analysis of randomized, controlled trials. 2008, 101(5): 508-16.

[95] Lee J, Seto D, Bielory L. Meta-analysis of clinical trials of probiotics for prevention and treatment of pediatric atopic dermatitis. J Allergy Clin Immunol 2008; 121:116-21.

[96] Boyle RJ, Bath-Hextall FJ, Leonardi-Bee J, Murrell DF, Tang ML. Probiotics for treating eczema. Cochrane Database Syst Rev. 2008; (4): CD006135.

[97] Williams HC, Grindlay DJ. What's new in atopic eczema? An analysis of systematic reviews published in 2007 and 2008. Part 2. Disease prevention and treatment. Clin Exp Dermatol. 2010; 35(3): 223-7.

[98] Ogden NS, Bielory L. Probiotics. A complementary approach in the treatment and prevention of pediatric atopic disease. Curr Opin Allergy Clin Immunol 2005, 5(2):179-84.

[99] Batchelor JM, Grindlay DJ, Williams HC. What's new in atopic eczema? An analysis of systematic reviews published in 2008 and 2009. Clin Exp Dermatol. 2010; 35(8): 8237; quiz 827-8. doi: 10.1111/j.1365-2230.2010.03901.x.

[100] Ishibashi N, Yamazaki S. Probiotics and safety. Am J Clin Nutr. 2001; 73(Suppl): 465S- 470S.

[101] Kunz AN, Noel JM, Fairchok MP. Two cases of Lactobacillus bacteremia during probiotic treatment of short gut syndrome. J Pediatr Gastroenterol Nutr 2004; 38: 457-8.

[102] Land MH, Rouster-Stevens K, Woods CR, Cannon ML, Cnota J, Shetty AK. Lactobacillus sepsis associated with probiotic therapy. Pediatrics. 2005; 115(1): 178-81.

[103] Thompson C, McCarter YS, Krause PJ, Herson VC. Lactobacillus acidophilus sepsis in a neonate. J Perinatol. 2001; 21(4):258-60.

[104] Broughton RA, Gruber WC, Haffar AA, Baker CJ. Neonatal meningitis due to Lactobacillus. Pediatr Infect Dis. 1983; 2(5): 382-4.

[105] Maassen CB, Claassen E. Strain-dependent effects of probiotic lactobacilli on EAE autoimmunity.Vaccine. 2008; 26(17): 2056-7. 
[106] Food and Agriculture Organization, World Health Organization. The Food and Agriculture Organization of the United Nations and the World Health Organization Joint FAO/WHO Working Group report on drafting guidelines for the evaluation of probiotics in food. FAO/WHO Report No. 4-30-2002.

[107] Salminen S, von Wright A, Morelli L et al. Demonstration of safety of probiotics: a review. Int J Food Microbiol 1998; 44:93-106.

[108] Kukkonen AK, Kuitunen M, Savilahti E, Pelkonen A, Malmberg P, Mäkelä M. Airway inflammation in probiotic-treated children at 5 years. Pediatr Allergy Immunol. 2011; 22(2): 249-51. doi: 10.1111/j.1399-3038.2010.01079.x

[109] Baken KA, Ezendam J, Gremmer ER, de Klerk A, Pennings JL, Matthee B, et al. Evaluation of immunomodulation by Lactobacillus casei Shirota: immune function, autoimmunity and gene expression. Int J Food Microbiol. 2006; 112(1): 8-18.

[110] Okitsu-Negishi S, Nakano I, Suzukim K, Hashira S, Abe T, Yoshino K. The induction of cardioangitis by Lactobacillus casei cell wall in mice: I. The cytokine production from murine macrophages by Lactobacillus casei cell wall extract. Clin. Immunol. Immunopathol. 1996; 78: 30-40.

[111] Prescott SL, Björkstén B. Probiotics for the prevention or treatment of allergic diseases. J Allergy Clin Immunol. 2007; 120(2): 255-262.

[112] Chapman CM, Gibson GR, Rowland I.Health benefits of probiotics: are mixtures more effective than single strains? Eur J Nutr. 2011; 50(1): 1-17.

[113] Van Huynegem K, Loos M, Steidler L. Immunomodulation by genetically engineered lactic acid bacteria. Front Biosci. 2009; 14: 4825-35.

[114] Egervärn M, Roos S, Lindmark H. Identification and characterization of antibiotic resistance genes in Lactobacillus reuteri and Lactobacillus plantarum. J Appl Microbiol. 2009; 107(5): 1658-68.

[115] Despande GC, Rao SC, Keil AD, Patole SK. Evidence based guidelines for use of probiotics in preterm neonates. BMC Med. 2011; 9(1): 92.

[116] Elias J, Bozzo P, Einarson A. Are probiotics safe for use during pregnancy and lactation? Can Fam Physician. 2011; 57(3): 299-301.

[117] Marko Kalliomäki, Jean-Michel Antoine, Udo Herz, Ger T. Rijkers, Jerry M. Wells, Annick Mercenier. Guidance for Substantiating the Evidence for Beneficial Effects of Probiotics: Prevention and Management of Allergic Diseases by Probiotics. J. Nutr. 2010; 140: 713S-721S.

[118] Shida K, Nanno M, Nagata S. Flexible cytokine production by macrophages and T cells in response to probiotic bacteria: a possible mechanism by which probiotics exert multifunctional immune regulatory activities. Gut Microbes. 2011; 2(2): 109-14. 


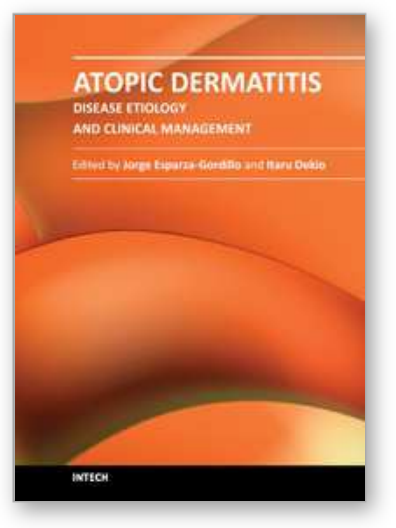

\author{
Atopic Dermatitis - Disease Etiology and Clinical Management \\ Edited by Dr. Jorge Esparza-Gordillo
}

ISBN 978-953-51-0110-9

Hard cover, 414 pages

Publisher InTech

Published online 22, February, 2012

Published in print edition February, 2012

Atopic Dermatitis is a common disease characterized by inflamed, itching and dry skin. This relapsing allergic disorder has complex etiology and shows a remarkably high clinical heterogeneity which complicates the diagnosis and clinical management. This book is divided into 4 sections. The first section (Disease Etiology) describes some of the physiological mechanisms underlying Atopic Dermatitis, including alterations in the immune system and the skin-barrier function. The important role of host-microorganism interactions on the pathophysiology of Atopic Dermatitis is discussed in the second section (Microorganisms in Atopic Dermatitis). An overview of the clinical diagnostic criteria and the disease management protocols commonly used is given in the third section (Diagnosis and Clinical Management). The last section (New Treatments) describes new therapeutic approaches that are not widely used but are currently being studied due to preliminary evidence showing a clinical benefit for Atopic Dermatitis.

\title{
How to reference
}

In order to correctly reference this scholarly work, feel free to copy and paste the following:

Öner Özdemir (2012). The Role of Probiotics in Atopic Dermatitis Prevention and Therapy, Atopic Dermatitis Disease Etiology and Clinical Management, Dr. Jorge Esparza-Gordillo (Ed.), ISBN: 978-953-51-0110-9, InTech, Available from: http://www.intechopen.com/books/atopic-dermatitis-disease-etiology-and-clinicalmanagement/the-role-of-probiotics-in-atopic-dermatitis-therapy-and-prevention

\section{INTECH}

open science | open minds

\section{InTech Europe}

University Campus STeP Ri

Slavka Krautzeka 83/A

51000 Rijeka, Croatia

Phone: +385 (51) 770447

Fax: +385 (51) 686166

www.intechopen.com

\section{InTech China}

Unit 405, Office Block, Hotel Equatorial Shanghai

No.65, Yan An Road (West), Shanghai, 200040, China

中国上海市延安西路65号上海国际贵都大饭店办公楼 405 单元

Phone: +86-21-62489820

Fax: +86-21-62489821 
(C) 2012 The Author(s). Licensee IntechOpen. This is an open access article distributed under the terms of the Creative Commons Attribution 3.0 License, which permits unrestricted use, distribution, and reproduction in any medium, provided the original work is properly cited. 